\title{
Effects of Sea Spray on the Dynamics and Microphysics of an Idealized Tropical Cyclone
}

\author{
J. SHPUnd, A. KHAIn, AND D. RosenFELD \\ Institute of Earth Sciences, Hebrew University of Jerusalem, Jerusalem, Israel
}

(Manuscript received 4 September 2018, in final form 11 March 2019)

\begin{abstract}
The effect of sea spray particles (SSP) on the intensity and microphysical structure of an idealized tropical cyclone (TC) is investigated using the Weather Research and Forecasting Model with a new spectral bin microphysics package. The SSP size distribution in the hurricane boundary layer is calculated using a Lagrangian-Eulerian bin-microphysics model (LEM) with high spatial resolution and extremely high drop size resolution. Sea spray ascending in updrafts within the eyewall of a TC dramatically increases the concentration of cloud drops within a wide range of sizes and decreases the effective drop radius to the values typical of polluted continental clouds. At the same time, the presence of spray drops of a few hundred microns in radii trigger intense rain just above cloud base. As a result, sea spray creates clouds that have a unique combination of maritime and continental properties. Outside the eyewall, clouds remain extremely maritime. SSP are shown to increase substantially the maximum vertical velocity, the cloud water content, and the mass contents of ice particles within the eyewall. As a result, SSP lead to TC intensification, axis symmetrization, and a decrease in eyewall radius. We found a new mechanism where wind-generated sea spray particles invigorate the inner cloud bands by nucleating more cloud droplets, which leads to more water vapor condensation and greater latent heating. The dependence of this process on surface wind speed constitutes a positive feedback loop that can lead to higher hurricane intensity. The results of simulations of cloud microstructure in the hurricane eyewall are supported by observations.
\end{abstract}

\section{Introduction}

Tropical cyclones (TC) are strikingly large organized convective vortices that still conceal many secrets regarding their emergence, intensification, mature evolution, and decay. Any theory of TC development stresses the importance of two main mechanisms: 1) atmosphericocean interaction determining the fluxes of heat, moisture, and momentum at the ocean surface and 2) the latent heat release in deep convective clouds forming the TC eyewall. One of the possible causes of the low accuracy in forecasting a TC intensity lies in the shortcomings of TC-ocean interaction descriptions (Emanuel 1989, 2003; Gall et al. 2008; Li 2004; Perrie et al. 2005; Wang et al. 2001). An important component of the TC-ocean interaction is sea spray generation within the surface layer at strong winds. A wide spectrum of sea spray particles (SSP) is generated during wave-breaking events-the size range of sea spray droplets can range

Corresponding author: Alexander Khain, alexander.khain@ mail.huji.ac.il from $\sim 0.01$ to $\sim 600 \mu \mathrm{m}$ (Clarke et al. 2006; Fairall et al. 2009; Gong 2003; Mårtensson et al. 2003; Ovadnevaite et al. 2014; Veron 2015). The concentration of the SSP can exceed several hundred per cubic centimeter.

In the context of the ocean-atmosphere interfacial effect on TC, it has been suggested that SSP effects might explain the observed surface winds by reducing the air-sea drag coefficient (Bell et al. 2012; Donelan et al. 2004; Powell et al. 2003). The evaluations of the SSP effect on the drag coefficient were performed in a set of theoretical and numerical studies (Andreas 2004; Bao et al. 2011; Bye and Jenkins 2006; Kudryavtsev and Makin 2011; Liu et al. 2012; Mueller and Veron 2014b; Soloviev and Lukas 2010). SSP can also play a role in mediating the sensible and the latent surface heat fluxes (Andreas and Decosmo 2002; Andreas and Decosmo 1999; Andreas 1992, 2011; Edson et al. 1996; Mueller and Veron 2010, 2014a,b). These two SSP effects are active within the lowest tens of meters of the hurricane boundary layer (HBL) and have been investigated using $1 \mathrm{D}$ models of the hurricane surface and boundary layer (e.g., Fairall et al. 1994; Bao et al. 2011; 
Bianco et al. 2011; Fairall et al. 2009; Kepert et al. 1999; Mueller and Veron 2010, 2014b). Soloviev et al. (2015) took into account the combined effects of spray and surface waves on the surface fluxes.

Many studies have stressed the role of large eddies (LE) or roll vortices on the dynamics of the HBL, and even on TC intensity (Foster 2005; Gao et al. 2017; Gao and Ginis 2014, 2016; Ginis et al. 2004; Lorsolo et al. 2008; Zhang et al. 2008; Zhu 2008). In a set of studies by Shpund et al. (2011, 2012, 2014), the thermodynamical and microphysical effects of SSP were investigated within the whole depth of the HBL using a 2D Lagrangian-Eulerian bin-microphysics model (LEM). It was shown that LE with spatial scales from several hundred meters to a few kilometers and characteristic perturbation vertical velocities of $1-3 \mathrm{~m} \mathrm{~s}^{-1}$ transport a broad spectrum of spray drops upward to heights of several hundred meters to the top of the HBL. About $30 \%$ of largest SSP and nearly all smallest SSP reach cloud-base level around $400 \mathrm{~m}$. Because of their salinity, SSP in the HBL grow at subsaturation conditions, which leads to a small increase in the HBL temperature, affecting the sensible and the latent surface heat fluxes.

Multiple TC simulations using different cloudresolving models have demonstrated that TC intensity is highly sensitive to the formulation of microphysical processes (Khain et al. 2015, 2016; Lynn et al. 2016). Cloud hydrometeors form and grow because of the deviation of water vapor pressure from the saturated value. TC sensitivity to different microphysical parameterization schemes is caused, in part, by the differences in supersaturation values predicted by different schemes (Khain et al. 2015). The most sophisticated cloud-resolving models have shown that the dynamics and microphysics of clouds are sensitive to aerosols (see reviews by Khain 2009; Khain et al. 2015; Tao et al. 2012). The cloud-resolving Weather Research and Forecasting (WRF) Model and the Regional Atmospheric Modeling System (RAMS) have been used to simulate the effects of aerosols on TC intensity and structure (Carrio and Cotton 2011; Cotton et al. 2007; Herbener et al. 2014; Khain et al. 2010, 2016; Lynn et al. 2016; Rosenfeld et al. 2012; Qu et al. 2017). It has been predicted that aerosols serving as cloud condensation nuclei (CCN) intensify the TC if the $\mathrm{CCN}$ penetrate the clouds at the center of the TC but weaken it if they penetrate the clouds at the TC periphery. SSP are often considered to be giant or ultragiant $\mathrm{CCN}$ that accelerate precipitation formation (e.g., Rosenfeld et al. 2002). In a recent study by Hoarau et al. (2018), the effects of SSP on intensity of TC Dumile were simulated. According to results of the study, SSP assumed to be small CCN are necessary to support intensity of the TC, which rapidly weakened in the absence of the SSP source.

To our knowledge, the effects of SSP with realistically wide size distribution on cloud microphysical structure and the intensity of tropical cyclones were not considered in literature.

Being wide, the size distribution of suspended SSP differs substantially from that of the environmental "background" maritime aerosols typically used to study the effects of aerosols on TC structure and intensity. The SSP concentration and SSP size distribution width increases with the maximum surface wind speed. Therefore, SSP concentration should be highest at the radii of maximum winds (i.e., in the eyewall zone). One can expect, therefore, that SSP would be an important component in shaping the microphysical structure and dynamics of deep convective clouds in the eyewall of TCs, changes that may affect the intensity of TCs themselves.

Evidence of the microphysical effect that SSP might have on a TC's eyewall clouds was provided by satellite measurements of the effective drop radius $r_{\text {eff }}$ in tops of growing clouds in more than 20 TCs using the approach developed by Rosenfeld and Lensky (1998). For example, satellite measurements from the Aqua and Terra satellites made at cloud tops in the eyewalls of Hurricanes Epsilon (2005) and Frances (2004) showed $r_{\text {eff }}$ of $\sim 17$ and $\sim 13 \mu \mathrm{m}$ at the altitude corresponding to $10^{\circ} \mathrm{C}$ at maximum winds of $\sim 33$ and $\sim 50 \mathrm{~m} \mathrm{~s}^{-1}$, respectively. These values are typical rather of polluted continental clouds (Benmoshe et al. 2012; Freud and Rosenfeld 2012) and are much lower than those observed in maritime convective clouds outside of the eyewalls $(\sim 25 \mu \mathrm{m})$. The effective radius was found to decrease with increasing surface wind speeds. Hence, clouds in a TC eyewall that should be expected to have extreme maritime microphysical characteristics, in fact, demonstrate a drop size distribution (DSD) typical of continental clouds. Shpund et al. (2019, hereafter SKR) studied the effects of SSP on the microphysics and dynamics of single deep convective clouds under conditions typical of the eyewalls of hurricanes using a parcel model as well as the Hebrew University Cloud Model (HUCM), both with bin microphysics. It was shown that sea spray leads to a dramatic increase in droplet concentration and a corresponding decrease in $r_{\text {eff }}$. It was also shown that SSP lead to an increase in the rates of all microphysical processes, to an increase in cloud water content and cloud ice content, as well to an increase in maximum updrafts and in cloud-top height.

In the present study, we investigate the role of suspended SSP in shaping the microphysical structure and intensity of an idealized TC. 


\section{Model description and simulation design}

The effects of SSP on the vertical cloud microstructure as well as on the intensity of an idealized TC were investigated in simulations where the WRF Model with bin microphysics [Fast Spectral Bin Microphysics, version 2 (FSBM-2)] was coupled with the Lagrangian-Eulerian model of the hurricane boundary layer.

\section{a. Description of FSBM-2}

The idealized TC numerical experiments are conducted using the WRF, version 3.8.1. In all the simulations, the Yonsei University (YSU) planetary boundary layer (Hong et al. 2006) is used to parameterize turbulent vertical mixing. The radiation is calculated using the Dudhia scheme for shortwave (Dudhia 1989) and the Rapid Radiative Transfer Model (RRTM) for longwave radiation (Mlawer et al. 1997). The development and maintenance of the idealized tropical cyclone is simulated on a doubly periodic $f$ plane of $20^{\circ} \mathrm{N}$ (Coriolis parameter $f=5.0 \times 10^{-5} \mathrm{~s}^{-1}$ ), starting from a weak axisymmetric tropical cyclone-like vortex embedded within a quiescent environment, above the sea surface with homogenous and fixed SST of $27^{\circ} \mathrm{C}$. The TC is initialized in the thermal wind balance with the thermal profiles based on the Dunion moist tropical Atlantic hurricane season sounding (Dunion 2011). All the simulations use 55 vertical levels stretching logarithmically from the ocean surface at $1015 \mathrm{hPa}$ up to the model top of $20 \mathrm{~km}$. A triple-nested mesh is used with horizontal grid spacings of $9 \mathrm{~km}$ (outer grid), $3 \mathrm{~km}$ (middle grid), and $1 \mathrm{~km}$ (inner grid); the respective numbers of domain grid points are $480 \times$ $480,481 \times 481$, and $720 \times 720$. The innermost domain is large enough $(720 \mathrm{~km})$ to describe both the vortex inner core and the outer rainbands. The inner-nested grids are located at the center of their parent domains, and a vortex-following technique is used to allow for long time integration. The TC development was triggered by an initial Rankine vortex with maximum tangential wind of $15 \mathrm{~m} \mathrm{~s}^{-1}$ at the radius of $135 \mathrm{~km}$. The initial tangential wind is diminished to zero at the radius of $600 \mathrm{~km}$. A spectral binmicrophysics (SBM) version commonly referred to as the Fast Spectral Bin Microphysics [FSBM; or FSBM, version 1 (FSBM-1)] was developed and implemented in the WRF Model (Khain and Lynn 2009). FSBM-1 was widely used for investigation of aerosol effects on intensity and structure of TCs (Khain et al. 2010, 2016; Lynn et al. 2016). In the present study, a new version of the Fast Spectral Bin Microphysics scheme, FSBM-2, was used to calculate cloud microphysical processes in all three domains. FSBM-2 uses improved, debugged, and modified source codes. Major microphysical processes in the FSBM-2 are described in detail by Khain et al. (2004, 2016). The FSBM-2 calculates four size distributions for soluble aerosols serving as $\mathrm{CCN}$, cloud drops, aggregates (snow), and graupel/hail. Each size distribution is defined on a grid containing 33 massdoubling bins. The maximum size of raindrops corresponding to the thirty-third bin is $6.5 \mathrm{~mm}$ in diameter. All hydrometeor masses are calculated on identical mass grids, but different particle densities determine the differences in the bulk sizes. Small ice particles with radii below about $100 \mu \mathrm{m}$ in the snow size distribution are interpreted as ice crystals. Larger ice particles in the snow size distribution, including those formed by aggregation, are interpreted as snow (aggregates), with the density decreasing with increasing size, down to $0.03 \mathrm{~g} \mathrm{~cm}^{-3}$. For each value of supersaturation, the Kohler theory was used to calculate the critical CCN size. The dynamical time step of $5 \mathrm{~s}$ used in the innermost grid is separated into several microphysical time substeps to eliminate unrealistic supersaturation peaks that can arise because of vertical advection. All $\mathrm{CCN}$ with sizes exceeding the critical value are then activated and converted to droplets, as described by Khain et al. (2000). The corresponding bins of activated $\mathrm{CCN}$ are then assumed empty.

A semianalytical approach for solving a system of equations for supersaturation over liquid water and ice was used to very accurately calculate deposition and sublimation, as well as diffusional growth and evaporation (Khain and Sednev 1996). In this approach, the time integrals of supersaturation with respect to liquid water and to ice are calculated during each microphysical time substep to determine the changes in the masses of liquid drops and ice particles. Both physical and numerical considerations suggest that an accurate description of the diffusion growth requires the use of microphysical time substeps shorter than the phase relaxation time (Korolev and Mazin 2003; Khain and Pinsky 2018).

The calculation of the droplet immersion freezing rate is described using the approach proposed by Bigg (1953). Frozen droplets with radii exceeding $200 \mu \mathrm{m}$ are assigned to graupel/hail. Smaller frozen droplets are assigned to small snow. Secondary ice generation is represented by the Hallett-Mossop mechanism (Hallett and Mossop 1974; Mossop 1976).

The changes of hydrometeor size distributions resulting from collisions between drops, between drops and ice particles, and between ice particles themselves are calculated by solving stochastic collection equations (Khain and Sednev 1995, 1996) using Bott's (1998) method. 
The graupel-drop collision kernels and their height dependences are calculated as described by Pinsky et al. (2001) and Khain et al. (2004).

Collisions between ice crystals are described following studies by Khain and Sednev (1995) and Khain et al. (2004). Sticking efficiencies between ice crystals, ice crystals and snow, and snow and snow are temperature dependent and calculated following (Ilotoviz et al. 2018). Coalescence efficiencies between snow and graupel are assumed equal to zero.

The spontaneous breakup of raindrops is parameterized following the laboratory results by Kamra et al. (1991) and Srivastava (1971). The collisional breakup is described by solving the stochastic coagulation-breakup equation following Seifert et al. (2005), where breakup probability and fragments size distribution were taken following laboratory experiments by Beard and Ochs (1995), Brown (1997), and Low and List (1982). To avoid the formation of unrealistically large aggregates, the spontaneous breakup of snowflakes is included. We assumed that snowflakes exceeding $0.88 \mathrm{~cm}$ in diameter (i.e., the "equivalent" diameter of a spherical particle) may break spontaneously, with the probability of breaking increasing with size. The fragment mass is assumed to be half of the parent particle mass. The maximum snowflake diameter obtained by the model is about $2 \mathrm{~cm}$, which agrees with the measurements made by Heymsfield et al. (2015). Snow converts into graupel in two cases: 1 ) when a snow particle collides with a raindrop of larger mass and 2) when a snow aggregate collides with droplets of smaller mass but the environmental supercooled liquid water content (LWC) exceeds a threshold of $0.5 \mathrm{~g} \mathrm{~m}^{-3}$. Evaluations show that, at this threshold, the rimed fraction in snow rapidly grows, so snow density approaches the density of graupel.

The main mechanism of ice crystal formation at temperatures below $-38^{\circ} \mathrm{C}$ is the homogeneous freezing of small droplets. The freezing rate dramatically increases within the temperature range from $-37^{\circ}$ to $-38^{\circ} \mathrm{C}$ (e.g., Cantrell and Heymsfield 2005). Accordingly, we use a simple homogeneous droplet freezing parameterization: all drops at $T \leq-38^{\circ} \mathrm{C}$ freeze immediately. These frozen drops are converted to ice particles (crystals) of corresponding bins.

The melting process is described using a simple parameterization proposed by Fan et al. (2010) and used in several intercomparison studies (Fan et al. 2015, 2017). In this parameterization, each ice hydrometeor is separated into three size groups: $D=87$ or $D=89 \mu \mathrm{m}$ (small), $87<D<875 \mu \mathrm{m}$ or $89<D<823 \mu \mathrm{m}$ (medium), and $D>875$ or $D>823 \mu \mathrm{m}$ (large) for graupel or snow, respectively. The melting of particles belonging to the

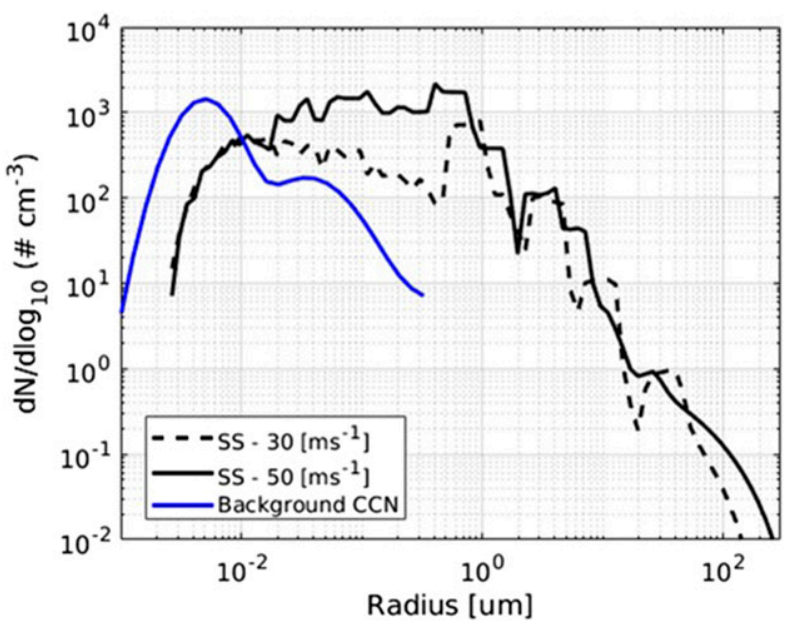

FIG. 1. Size distributions of SSP and background CCN used in simulations of a TC: initial background CCN size distribution for background maritime conditions (blue) and horizontally averaged equilibrium SSP simulated using LEM, taken at the level $z=350 \mathrm{~m}$, at $U_{10}=30 \mathrm{~m} \mathrm{~s}^{-1}$ (black dashed) and $U_{10}=50 \mathrm{~m} \mathrm{~s}^{-1}$ (black solid).The SSP size distributions are taken at the stage of approximate equilibrium, where the number of drops reaching the upper levels in updrafts became approximately equal to the number of drops leaving the levels by settling and in downdrafts.

first group is assumed to be immediate. Particles belonging to the second group lose $1 \%$ of their mass per second, whereas particles belonging to the third group lose $0.6 \%$ of their mass per second. These rates are chosen to produce reasonable melting distance below melting level. An ice particle's loss of mass is added into the corresponding bin of raindrop size distribution; that is, all water is assumed to be shed as drops with a mass equal to the mass of the meltwater generated at that time step. To calculate radar characteristics, a dualpolarimetric forward operator was used (Ryzhkov et al. 2011; Snyder et al. 2015). The operator allows us to calculate all main radar characteristics that can be measured by a dual-polarization radar network (e.g., WSR-88D in the United States).

In the simulation without SSP (NoSpray), the background size distribution of dry CCN typical of maritime atmosphere was used following Ghan et al. (2011). The size distribution of $\mathrm{CCN}$ is defined on a grid containing 43 mass-doubling bins with a maximum dry $\mathrm{CCN}$ radius of $2 \mu \mathrm{m}$. The initial CCN size distribution is given as the sum of three lognormal distributions representing the smallest CCN (Aitken mode, centered at $0.005 \mu \mathrm{m}$ ), medium-sized CCN (accumulation mode, centered at $0.035 \mu \mathrm{m}$ ), and largest CCN (coarse mode, centered at $0.31 \mu \mathrm{m}$ ) (Fig. 1, blue curve). The corresponding CCN concentrations in the modes are of 170,30 , and $1.5 \mathrm{~cm}^{-3}$. The total $\mathrm{CCN}$ concentration was, therefore, around 
$200 \mathrm{~cm}^{-3}$, while the fraction of $\mathrm{CCN}$ with radii exceeding $0.01 \mu \mathrm{m}$ was about $30 \mathrm{~cm}^{-3}$.

\section{b. Lagrangian-Eulerian model of the hurricane boundary layer}

In the simulation with SSP (Spray), SSP size distributions obtained in separate offline LEM simulations (Shpund et al. 2014; SKR) were added to the background CCN distribution within a layer of $600 \mathrm{~m}$ in depth. Shpund et al. (2014) includes a detailed description of the LEM and its application in simulating sea spray generation flux, as well as the microphysical evolution of the SSP within the HBL. The LEM is a slab-symmetric model with a computational area assumed to be perpendicular to the background TC wind. This configuration allows us to describe in detail the vertical transport of SSP by roll vortices elongated along the background wind (Ginis et al. 2004). The LEM computational area is covered with 3750 interacting adjacent Lagrangian air parcels with a characteristic linear size of $\sim 8 \mathrm{~m}$, which is indicative of the high spatial resolution of the simulations. These parcels follow the background wind as they move within a turbulent-like flow field generated by a turbulent model (which includes dissipation of turbulent fluctuations), in line with the data observed by Zhang et al. (2009).

The microphysics of each Lagrangian cloud parcel includes the diffusional growth-evaporation equation used for wetted aerosols and water drops as well as the equation for supersaturation and the stochastic collision equation describing collisions between drops (Magaritz et al. 2009; Pinsky and Khain 2002). The droplet size distribution of both nonactivated aerosol particles and cloud drops is calculated on a mass grid containing 500 bins within a radius range from 0.005 to $2000 \mu \mathrm{m}$. The high salinity of SSP enables them to grow at a relative humidity (RH) of $\sim 95 \%$, which in turn affects their thermodynamic behavior. The model takes into account the turbulent mixing between the Lagrangian parcels (Pinsky et al. 2010) as well as drop settling. The SSP fluxes and size distributions on the surface depend on the background wind $U_{10}$ at $z=10 \mathrm{~m}$. The SSP source functions (with radii ranging from $\sim 0.01$ to $\sim 600 \mu \mathrm{m}$ ) at different $U_{10}$ were determined by combining observed size distributions measured in real storms and those measured under laboratory conditions (Lewis and Schwartz 2004; Mårtensson et al. 2003; Gong 2003; Fairall et al. 2009).

The SSP size distributions were calculated by the LEM at surface wind speeds ranging from 20 to $50 \mathrm{~m} \mathrm{~s}^{-1}$. The maximum wind speeds in real TCs and in the simulations may be outside the range of SSP source observations. Because of the lack of the observational data about the SSP sources at surface winds exceeding $50 \mathrm{~m} \mathrm{~s}^{-1}$, for winds exceeding $50 \mathrm{~m} \mathrm{~s}^{-1}$, the SSP source was assumed equal to that at $50 \mathrm{~m} \mathrm{~s}^{-1}$. Note that large SSP at altitudes corresponding to the cloud base of the deep convective clouds are formed not only by vertical transport from the sea surface but also by efficient collisions of large SSP with smaller ones. An example of the "equilibrium" SSP size distributions simulated using the LEM at $U_{10}=30$ and $50 \mathrm{~m} \mathrm{~s}^{-1}$ at $z=350 \mathrm{~m}$ is shown in Fig. 1 (black lines). The size distributions shown in Fig. 1 are obtained when approximate quasi-equilibrium state is reached. The SSP concentration at $U_{10}=50 \mathrm{~m} \mathrm{~s}^{-1}$ is substantially higher than at $U_{10}=30 \mathrm{~m} \mathrm{~s}^{-1}$. In particular, the amount of SSP with radii larger than $7 \mu \mathrm{m}$ at $50 \mathrm{~m} \mathrm{~s}^{-1}$ wind is an order of magnitude higher than at the $30 \mathrm{~m} \mathrm{~s}^{-1}$ wind.

In Spray, the surface wind speeds at $z=10 \mathrm{~m}$ were calculated in each grid point of the WRF SBM (FSBM-2). In grid points where $U_{10}$ exceeded $20 \mathrm{~m} \mathrm{~s}^{-1}$, the SSP size distributions corresponding to the values of $U_{10}$ were implemented within the lower 600-m-depth layer. The equilibrium SSP distributions were updated at all grid points below cloud base at every dynamical time step depending on the $U_{10}$ wind speed.

The equilibrium SSP size distributions (output from the LEM) were implemented into the WRF spectral bin microphysics in the following way: the SSP containing "dry aerosols" with radii below $\sim 2 \mu \mathrm{m}$ were "assigned" to the corresponding bins of the background "dry" CCN size distribution. The size of each "dry mass" was calculated using the Atlantic Ocean salinity. The SSP containing larger dry aerosols were added to the drop size distribution.

The equilibrium SSP size distributions shown in Fig. 1 are calculated in the absence of convective rain from deep convective clouds. During the LEM calculation, only collisions and settling of SSP within the boundary layer (described by LEM) were taken into account. At the same time, the rain from deep convective clouds can take place in the regions of deep convection. To evaluate the effect convective rain on the SSP size distributions, a set of supplemental simulations were performed using the LEM, in which different rain rates at the upper LEM boundary were assumed. The study assumed the Marshall-Palmer distributions of raindrops. The results of the simulations indicate that raindrops scavenge not more than $20 \%-40 \%$ of the mass of the SSP that reach the cloud-base level (even at high rain rates of $50 \mathrm{~mm} \mathrm{~h}^{-1}$ ). There are several reasons for this comparatively low effect of rain on the SSP scavenging:

1) Relatively low concentrations of large spray drops and raindrops, as well as the low collision efficiency between raindrops and the smallest SSP. 
2) The trajectories associated with SSP and raindrops within the boundary layer in the presence of roll vortices are different: SSP ascends from lower levels within the updraft branches of the roll vortices. At the same time, the raindrops that are usually comparatively small $(<1 \mathrm{~mm})$ tend to fall in the downdraft branches of the rolls.

As a result, the characteristic time scale for SSP scavenging tends to be longer than the time needed to replenish the SSP size distribution within the layer below cloud-base level (e.g., the ascent of an SSP with radii of $300 \mu \mathrm{m}$ to around the $400-\mathrm{m}$ level within a $2 \mathrm{~m} \mathrm{~s}^{-1}$ updraft takes about 7-8 min, where the smallest SSP drop that still has significant settling velocity will reach $400 \mathrm{~m}$ after about $3 \mathrm{~min}$ ).

The effect of scavenging could have been parameterized in our study as a function of rain rate and wind speed. But for the sake of simplicity, as a first approximation, we decided to neglect this scavenging effect by raindrops for calculating the equilibrium-SSP size distributions in LEM. These SSP size distributions (as in Fig. 1) were then implemented into the boundary layer of an idealized TC at each time step and in each grid point depending on the surface wind $\left(>20 \mathrm{~m} \mathrm{~s}^{-1}\right)$. After assigning the equilibrium SSP into the TC boundary layer and conversion of the SSP size distribution to the CCN distribution and DSD (as discussed above), all dynamical and microphysical processes including advection, nucleation, and scavenging are taken into account explicitly through the idealized TC simulation. One can expect that in the sheared environmental flow typical of eyewalls, raindrops fall outside cloud updrafts. This effect decreases the SSP scavenging, allowing SSP ascend in cloud updrafts.

Since FSBM-2 does not take into account effects of salinity on drop growth/evaporation, it predicts evaporation and corresponding cooling in the boundary layer at $\mathrm{RH}<100 \%$. In contrast, SSP grow at a high relative humidity $(>\sim 95 \%)$ with corresponding heating of the boundary layer (BL) air (Shpund et al. 2014). To take (at least partially) the effect of the SSP salinity in FSBM-2, evaporation of SSP below cloud base of deep convective clouds was excluded. Accordingly, the evaporative cooling was also excluded. The increase in temperature due to SSP growth is not large and was not taken into account. Such an assumption as well as a limitation of the SSP production by $U_{10}=50 \mathrm{~m} \mathrm{~s}^{-1}$ leads, supposedly, to some underestimation of the SSP effect on the instability in the eyewall and on TC intensity. In the following section, we present a comparison between results of Spray and NoSpray performed for the 48-h period following the spinup time.

\section{The effects of sea spray on idealized TC}

In this study, we investigate the SSP effect on TC dynamics through their impact on cloud microphysics in deep convective clouds of the eyewall. Although the dynamical (velocities, pressure) and microphysical (cloud contents, concentrations) effects are closely related via latent heat release, mass loading, and other factors, we will generally consider first the microphysical effects of SSP and only thereafter their dynamical effects. However, since the SSP mass that penetrates clouds depends on vertical velocity, the microphysical and dynamical factors will occasionally be considered together.

\section{a. Microphysical effects of sea spray}

The initially axisymmetric vortex rapidly loses its symmetry and slowly intensifies as the radius of maximum winds decreases. Sixteen hours after the spinup time, the wind speed at $z=10 \mathrm{~m}$ did not exceed $20 \mathrm{~m} \mathrm{~s}^{-1}$, with the exception of some rare grid points; hence, no differences between NoSpray and Spray were observed. During this period, the magnitudes of updrafts in the BL were mostly well below $1 \mathrm{~m} \mathrm{~s}^{-1}$, which caused low cloud droplet concentrations in both simulations (not shown). The effects of sea spray injection became pronounced during the following $6 \mathrm{~h}$ as an axisymmetric eyewall structure was formed. Figure 2 shows early eyewall formation in Spray as seen from horizontal cross sections at $z=1 \mathrm{~km}$ in the fields of vertical velocity $(w)$, droplet concentration $\left(N_{d}\right)$, cloud water content (CWC; droplets with the radii below $50 \mu \mathrm{m})$, rainwater content (RWC; drops with the radii exceeding $50 \mu \mathrm{m}$ ), and number concentration of inactivated CCN $\left(N_{\mathrm{ccn}}\right)$ taken at different time instances from 17 to $24 \mathrm{~h}$.

After $17 \mathrm{~h}$ in Spray, $w$ has asymmetric spatial distribution as the eyewall only starts to form. As SSP continues ascending in updrafts, after $20 \mathrm{~h}$, an axisymmetric eyewall with a radius of $30 \mathrm{~km}$ forms, as can be clearly seen in the fields of $\mathrm{CCN}$ and $N_{d}$. At this time, multiple peripheral rainbands form as well. Both $N_{\mathrm{ccn}}$ and $N_{d}$ increase around the maximum prevailing winds. Since the cloud base, determined as the level where $\mathrm{RH}=100 \%$, is at the height of $400-500 \mathrm{~m}$, the $N_{\mathrm{ccn}}$ field at $z=1 \mathrm{~km}$ shows the concentration of nonactivated $\mathrm{CCN}$, while the $N_{d}$ field shows the number concentration of cloud droplets (i.e., activated $\mathrm{CCN}$ ). The area with high CCN number concentration and CWC increases with time following the increase in the $10-\mathrm{m}$-level wind. The maximum values of $N_{d}$ exceed $700 \mathrm{~cm}^{-3}$ at $t=24 \mathrm{~h}$.

The maximum values of CWC coincide with the areas of maximum $N_{d}$. At the same time, clouds with significant values of CWC and of RWC cover a much larger 

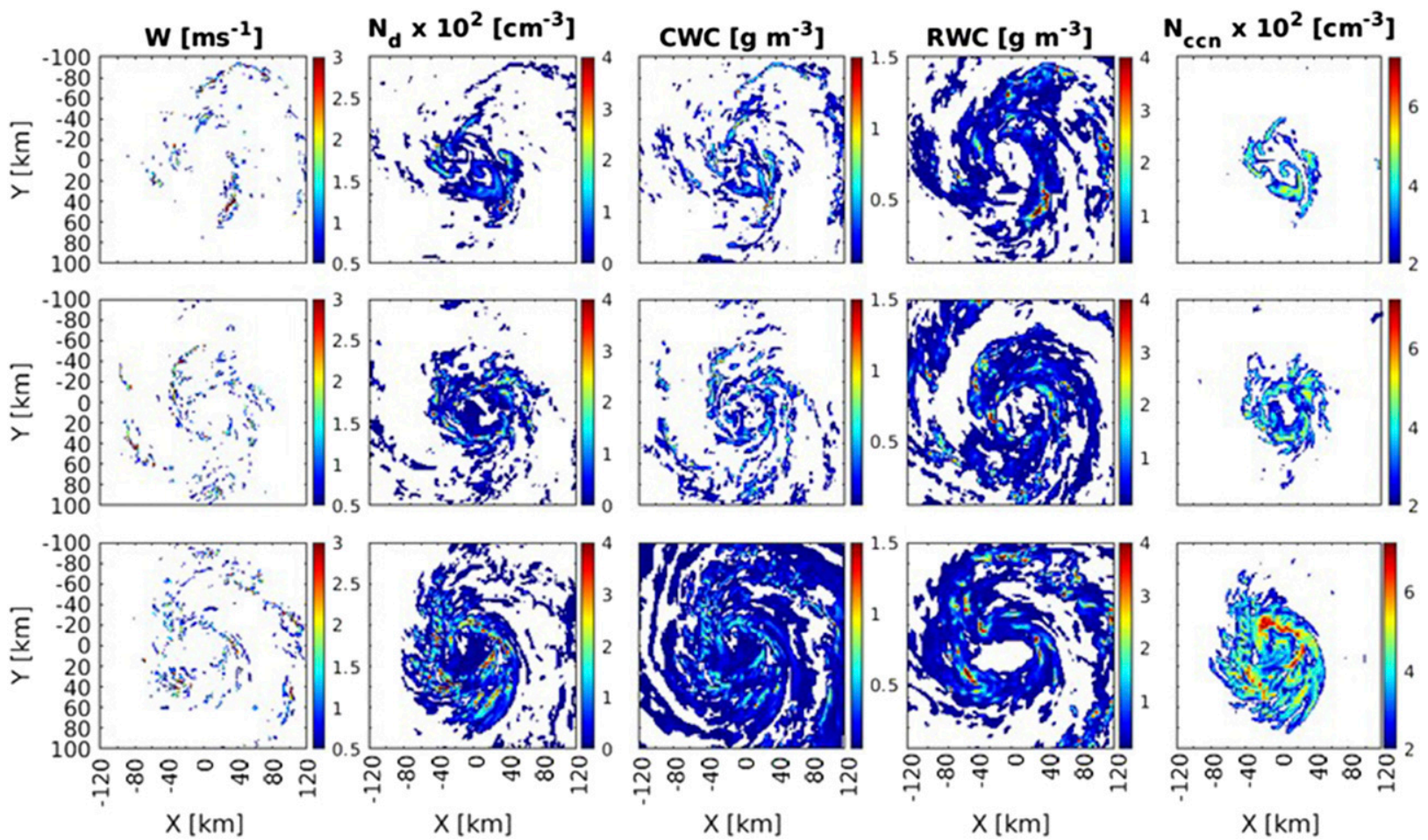

FIG. 2. Horizontal cross sections at $z=1 \mathrm{~km}$ in the fields of (left to right) vertical velocity ( $w)$, droplet concentration $\left(N_{d}\right)$, cloud water content (CWC), rainwater content (RWC), and CCN concentration at (top) 17, (middle) 20, and (bottom) $24 \mathrm{~h}$ in Spray. The CCN concentration field is plotted with a lower limit of $200 \mathrm{~cm}^{-3}$.

area than clouds with high $N_{d}$. Thus, there are clouds of two different microphysical properties in the TC region: eyewall clouds affected by SSP at $20-30 \mathrm{~km}$ from the storm center characterized by high droplet concentration and clouds at larger distances from the TC center with a much lower number concentration of droplets formed by activation of the background CCNs. This unique coexistence of clouds with two microphysical structures persists for the entire TC evolution. Strong convective rain does not prevent the growth of CWC and $N_{d}$ in the eyewall because a significant fraction of raindrops falls down either when distances from the TC center are larger than those corresponding to the maximum $N_{d}$ (i.e., because of the wind shear) or below the level of nucleation of new droplets within clouds. As it will be shown below (see also SKR), in Spray, cloud droplets form by in-cloud nucleation at all levels, including those at large distances above cloud base. At the same time the existence of large SSP leads to formation of intense rain at low levels. These raindrops do not decrease CWC, which is located above this level.

Figure 3 shows the same fields as Fig. 2, but in NoSpray at $t=24 \mathrm{~h}$. A dramatic difference is seen in the microphysical fields: the droplet concentration is low $\left(\sim 10 \mathrm{~cm}^{-3}\right)$, which is typical of extreme maritime conditions. The maritime $\mathrm{CCN}$ size distribution has three

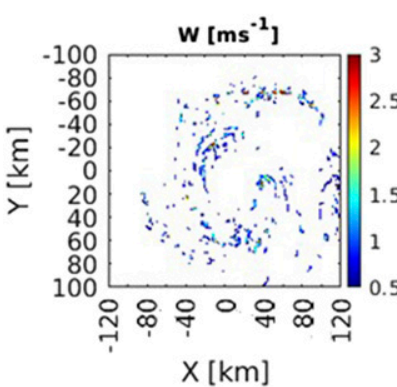

$\mathrm{X}[\mathrm{km}]$
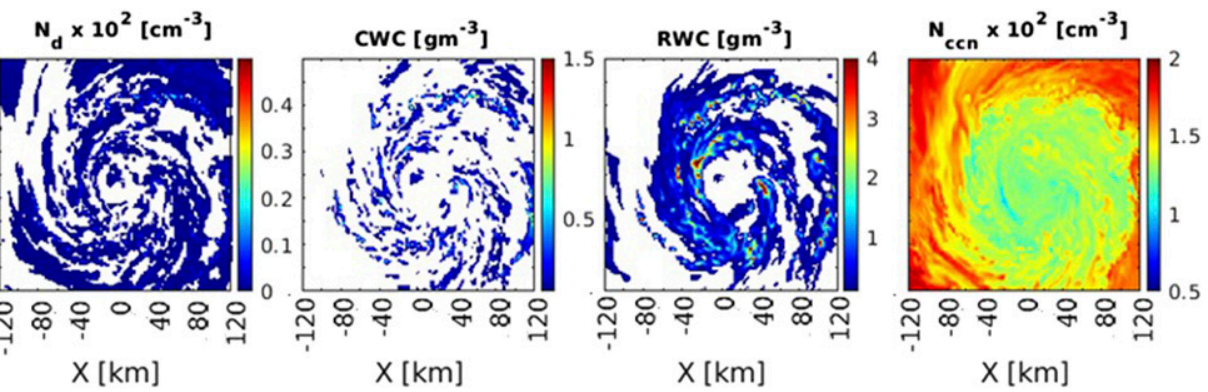

FIG. 3. As in Fig. 2, but for NoSpray at $t=24 \mathrm{~h}$. 

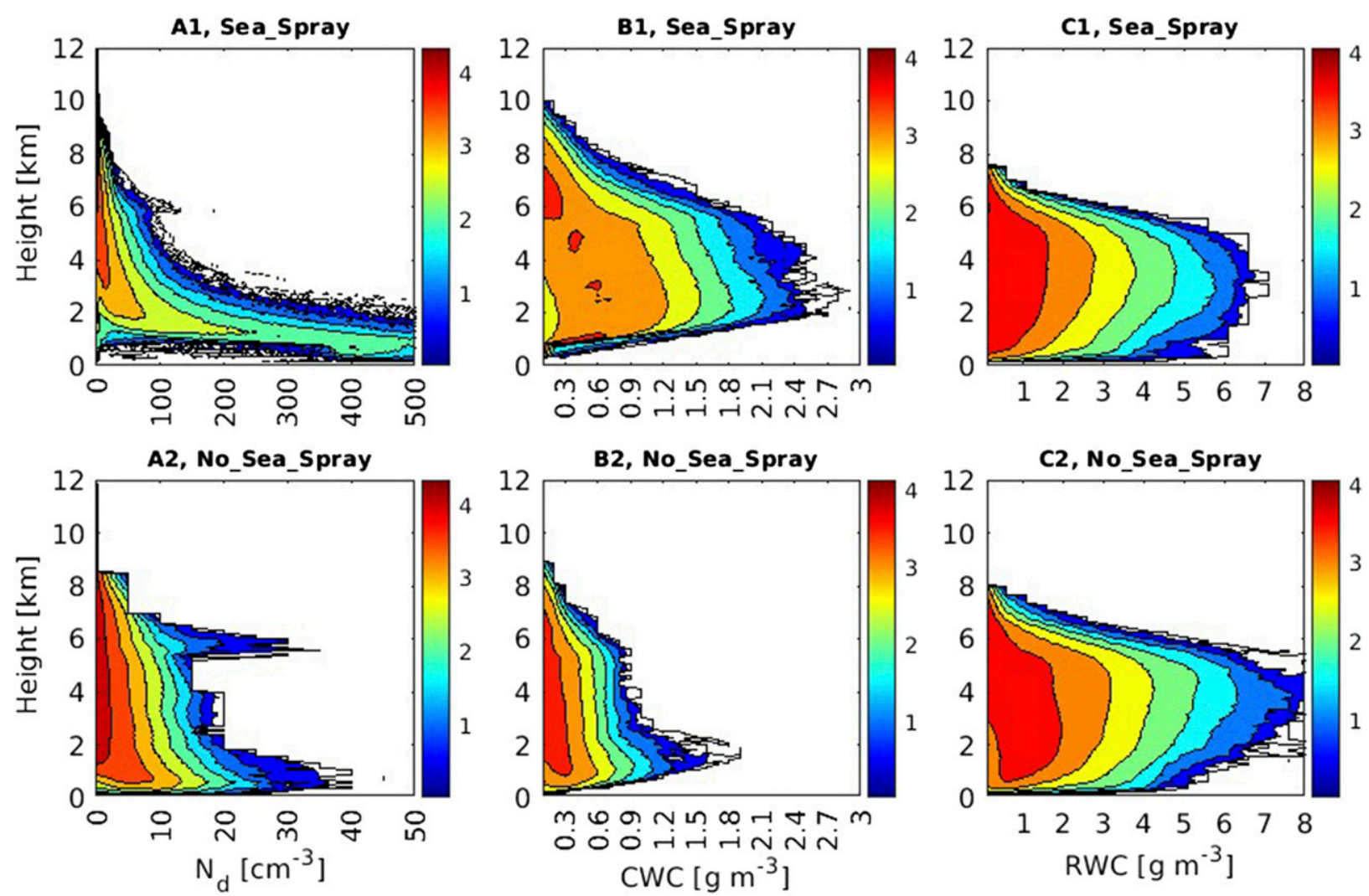

FIG. 4. CFAD of the fields of (left) $N_{d}$, (center) CWC, and (right) RWC in (top) Spray and (bottom) NoSpray. Color scales show decimal $\operatorname{logs}\left(\right.$ e.g., $\log _{10}$ ) of gridpoint number (counts) with the corresponding values, falling within a certain interval corresponding to each field. The calculations were performed across the entire innermost domain and along the simulation time with 1-h output time interval. For clarity, in Spray where the $x$ axis was limited to $500 \mathrm{~cm}^{-3}, N_{d}$ ranges from 0 to $1500 \mathrm{~cm}^{-3}$. In NoSpray, $N_{d}$ ranges from 0 to $50 \mathrm{~cm}^{-3}$. An identical interval of $5 \mathrm{~cm}^{-3}$ was used for comparison. The CFAD for CWC was plotted with a resolution of $0.1 \mathrm{~g} \mathrm{~m}^{-3}$ within the range from 0 to $3 \mathrm{~g} \mathrm{~m}^{-3}$. The CFAD for RWC was plotted with a resolution of $0.5 \mathrm{~g} \mathrm{~m}^{-3}$ within the range from 0 to $8.0 \mathrm{~g} \mathrm{~m}^{-3}$.

modes centered at radii of $0.005,0.035$, and $0.31 \mu \mathrm{m}$ with corresponding concentrations of 170,30 , and $1.5 \mathrm{~cm}^{-3}$. The concentration of inactivated $\mathrm{CCN}$ at $z=1 \mathrm{~km}$ at a radial distance of $80 \mathrm{~km}$ from the TC center is about $100 \mathrm{~cm}^{-3}$. Taking into account that initial total CCN concentration was about $200 \mathrm{~cm}^{-3}$ (such concentration is seen at radial distances exceeding $80-100 \mathrm{~km}$ from the TC center), the concentration of activated $\mathrm{CCN}$ can be evaluated as $\sim 100 \mathrm{~cm}^{-3}$. Taking into account the distribution of $\mathrm{CCN}$ between different modes, one can conclude that all CCN belonging to the third and second modes, as well as a significant fraction of the smallest $\mathrm{CCN}$ of the first mode, are activated just above cloud base. This limits the potential of in-cloud nucleation at higher levels in NoSpray. The eyewall in NoSpray develops more slowly and is less pronounced and concentrated, compared to Spray.

Figure 4 shows contoured frequency by altitude diagrams (CFAD) of $N_{d}, \mathrm{CWC}$, and RWC in Spray and NoSpray. The CFAD provides an overview of the entire simulation by presenting a distribution of the given field over height across the innermost domain and over the simulation time (e.g., the output with 1-h time interval). The figure is plotted for the model grid points where the total wind speed exceed $25 \mathrm{~m} \mathrm{~s}^{-1}$ and $w>1 \mathrm{~m} \mathrm{~s}^{-1}$. One can see that $N_{d}$ in Spray exceeds $500 \mathrm{~cm}^{-3}$ (the $N_{d}$ maximum in Spray is about $1500 \mathrm{~cm}^{-3}$ ), which is more than one order of magnitude larger than in NoSpray. High CWC values of more than $2.1 \mathrm{~g} \mathrm{~m}^{-3}$ in Spray take place within a wide range of altitudes from 2 to about $6 \mathrm{~km}$. In contrast, the maximum CWC in NoSpray is about $1.5 \mathrm{~g} \mathrm{~m}^{-3}$ and rapidly decreases with height to about $0.7 \mathrm{~g} \mathrm{~m}^{-3}$. The larger values of CWC in Spray suggest that latent heat release is larger in the eyewall in Spray compared to NoSpray, as more droplets penetrating higher levels continue growing by diffusion. The relationship between the aerosol-induced increase in CWC and the increase in latent heat release was investigated in multiple studies: for instance, in bin-microphysics simulations by Khain et al. (2004, 2005, 2008, 2010), detailed overview by Khain (2009) with detailed analysis of heat and moisture budgets, analytical considerations by Pinsky et al. (2012, 2013, 2014), 

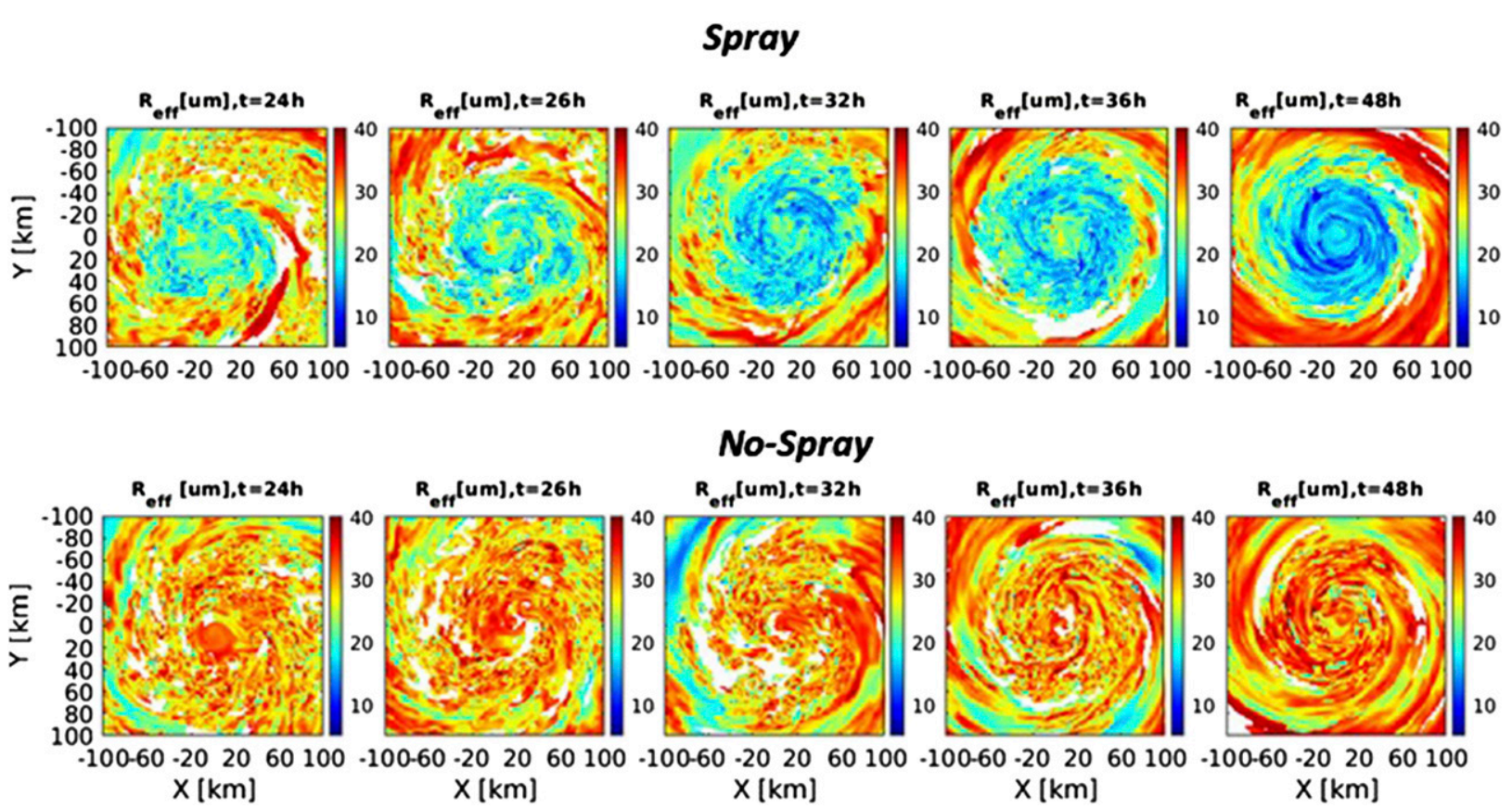

FIG. 5. Horizontal cross sections of the field of the effective radius at $z=2 \mathrm{~km}$ in (top) Spray and (bottom) NoSpray at (left to right) $t=24$, $26,32,36$, and $48 \mathrm{~h}$.

and LESs of warm Cu by Khain et al. (2019). The book by Khain and Pinsky (2018) summarizes the results obtained in this field.

Remarkably, the RWC in Spray and NoSpray are quite similar except for the larger rain mass occurring at around $4 \mathrm{~km}$ in NoSpray. In Spray, the RWC peaks are closer to the level where SSP penetrate clouds. Microphysical cloud structure characterized both by large CWC and large $N_{d}$ up to high altitudes and the occurrence of intense warm rain (caused by drop-drop collisions and, especially, SSP-drop collisions) is a unique feature of eyewall deep convective clouds as simulated in the study. Similar microphysical features were reported in SKR in a $50 \mathrm{~m} \times 50 \mathrm{~m}$ resolution simulation of SSP-affected deep convective clouds.

The similarity between eyewall clouds and polluted continental convective clouds seen in Spray is further supported by the values of $r_{\text {eff }}$. The vertical profiles of $r_{\text {eff }}$ in continental and maritime clouds under different aerosol concentrations were investigated in several observations (Freud et al. 2008; Freud and Rosenfeld 2012; Khain et al. 2013; Prabha et al. 2011) and simulated using SBM cloud models (Benmoshe et al. 2012; Khain et al. 2013). These studies show that, in continental clouds characterized by high CCN concentration, $r_{\text {eff }}$ is smaller and increases with height more slowly than in clean-air maritime convective clouds. It was also found that first raindrops form at a distance from the cloud base where $r_{\text {eff }}$ exceeds its threshold value of 13-15 $\mu \mathrm{m}$.
The physical reason for this threshold value can be attributed to the fact that the collision kernel is proportional to about $r_{\text {eff }}^{5}$ (Freud et al. 2011; Freud and Rosenfeld 2012). As SKR has demonstrated using a parcel model and the HUCM, $r_{\text {eff }}$ in clouds with SSP is substantially lower in Spray than in NoSpray. Consistent results are obtained in the present study. Figure 5 shows the horizontal cross section of the effective radius field at $z=2 \mathrm{~km}\left(T \sim 10^{\circ} \mathrm{C}\right)$ in NoSpray and Spray at different time instances. One can see that at this height $r_{\text {eff }}$ in eyewall updrafts is below $10-15 \mu \mathrm{m}$, which is typical of very polluted continental clouds. The value of $r_{\text {eff }}$ gets smaller as the maximum wind speed increases and more SSP are injected into the HBL. At the beginning, only fractions of the outer part of the eyewall were affected, but as the wind speed increases, $r_{\text {eff }}$ decreases over larger area while remaining the lowest in the eyewall. Figure 5 shows, accordingly, that both $r_{\text {eff }}$ decreases and the area of small values of $r_{\text {eff }}$ increases during TC intensification. Outside the area where SSP are generated, clouds in Spray are mostly maritime with high values of $r_{\text {eff }}$ (Figs. 5 and 6).

Figure 6 shows vertical cross section through the TC center in the fields of droplet effective radius at $t=48 \mathrm{~h}$ in NoSpray and Spray. One can see that, in NoSpray, the microphysical structure of clouds in the eyewall does not differ from that of clouds outside the eyewall. In Spray, the microphysical structure of clouds in the eyewall dramatically differs from that of clouds outside of it. 

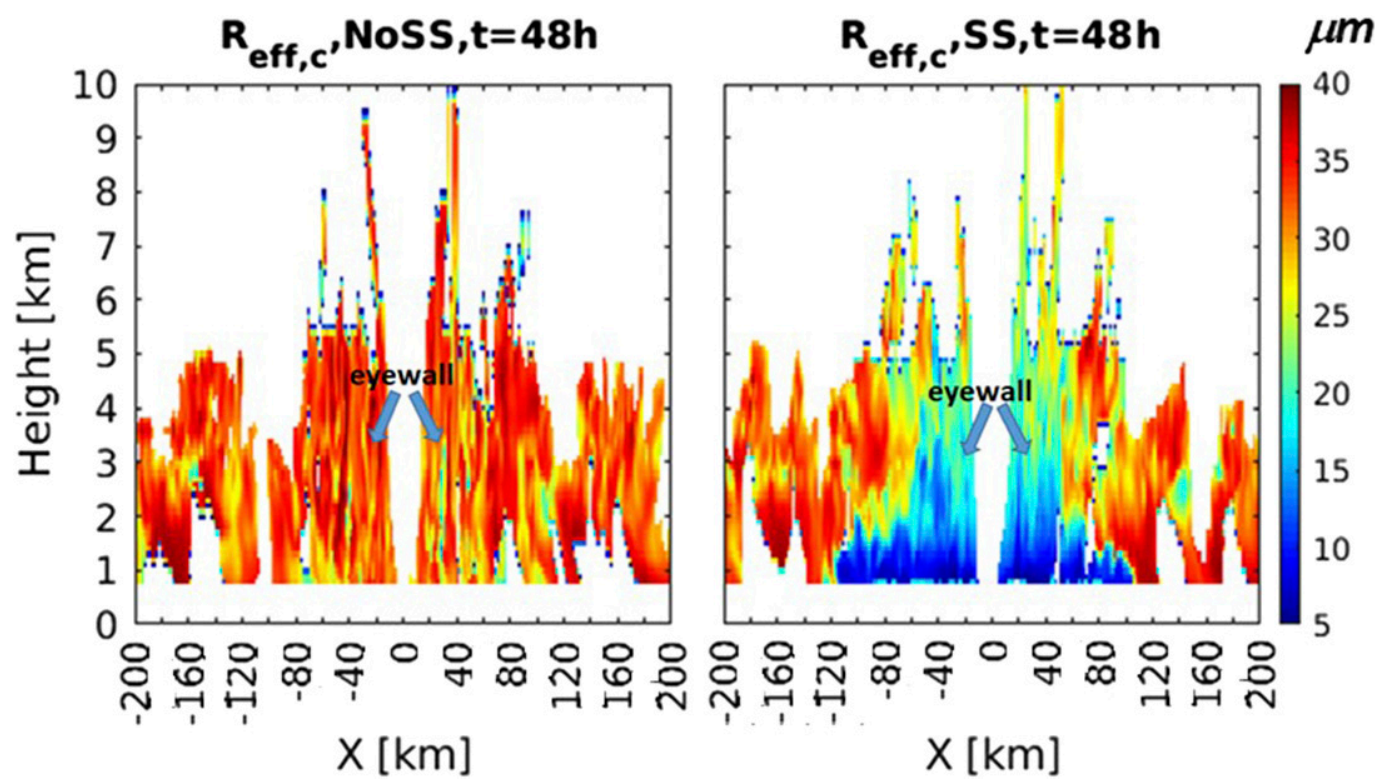

FIG. 6. Vertical cross section through the TC center in the fields of droplet effective radius at $t=48 \mathrm{~h}$ in (left) NoSpray and (right) Spray.

Such a difference in the microphysical structure is seen not only in a particular TC cross section but also in the azimuthally averaged values of the effective droplet radius, as shown in Fig. 7.

While, in NoSpray, clouds are extremely maritime, with $r_{\text {eff }}$ exceeding $35 \mu \mathrm{m}$, in Spray, $r_{\text {eff }}$ in clouds within the eyewall does not exceed $15-20 \mu \mathrm{m}$ up to the $6-\mathrm{km}$ level. Even droplets reaching the 10-km level (the homogenous freezing level is around $11 \mathrm{~km}$ ) have an average $r_{\text {eff }}$ between 20 and $25 \mu \mathrm{m}$, which is much lower than the corresponding NoSpray values. SKR analyzes in detail this behavior of $r_{\text {eff }}$, where the effects of SSP on single deep convective clouds are analyzed using LES. The low $r_{\text {eff }}$ values in these clouds are determined by two main factors: (i) the high concentration of small droplets being advected upward and (ii) the in-cloud nucleation of new droplets from the smallest CCN. As was mentioned above, the SSP distribution contains a significant amount of very small SSP that are activated at higher levels, where supersaturation increases because of an
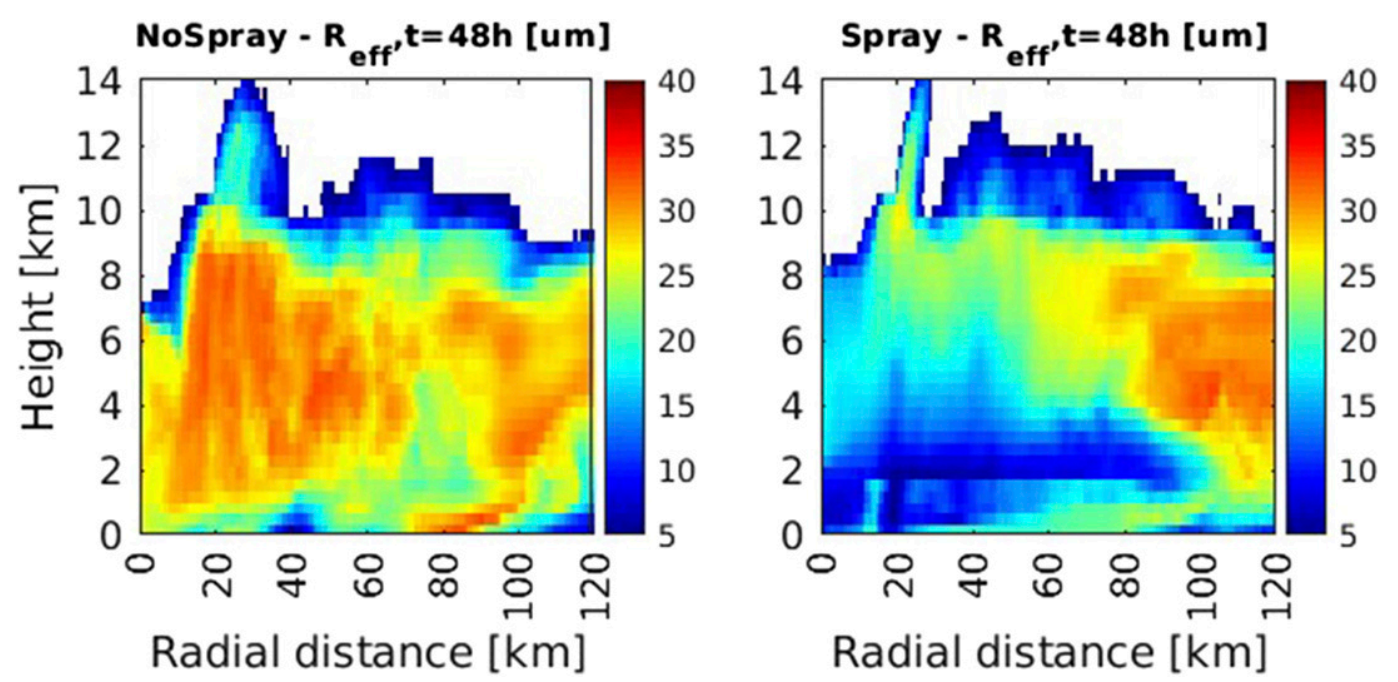

FIG. 7. Height-radial cross section of the azimuthally averaged effective droplet radius field at $t=48 \mathrm{~h}$ in (left) NoSpray and (right) Spray. 


\section{Spray}
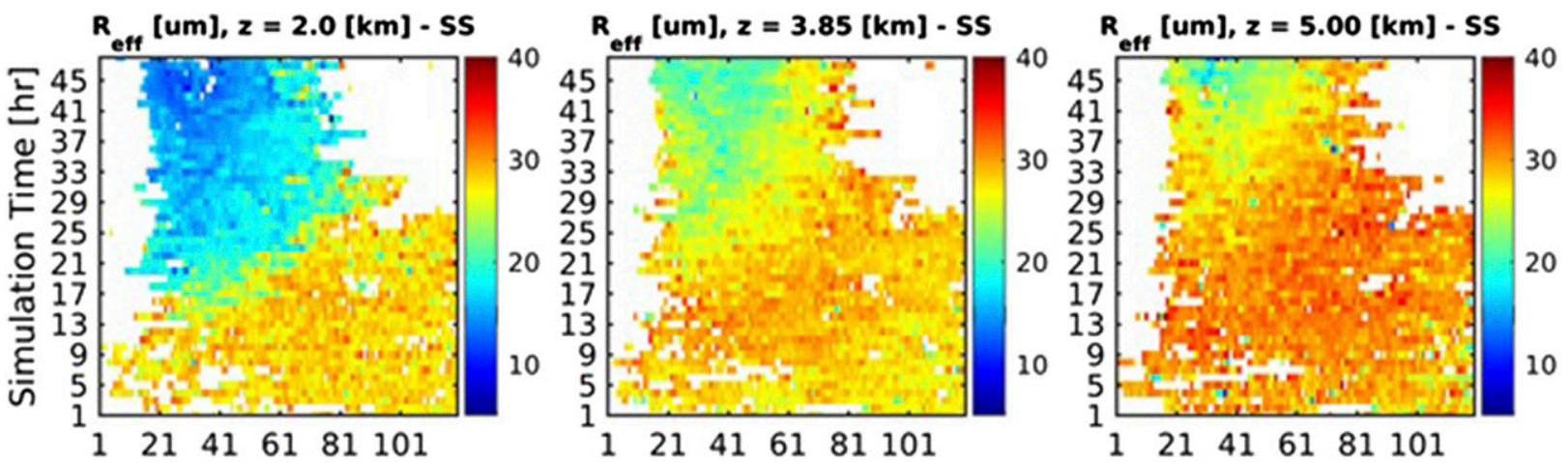

No-Spray
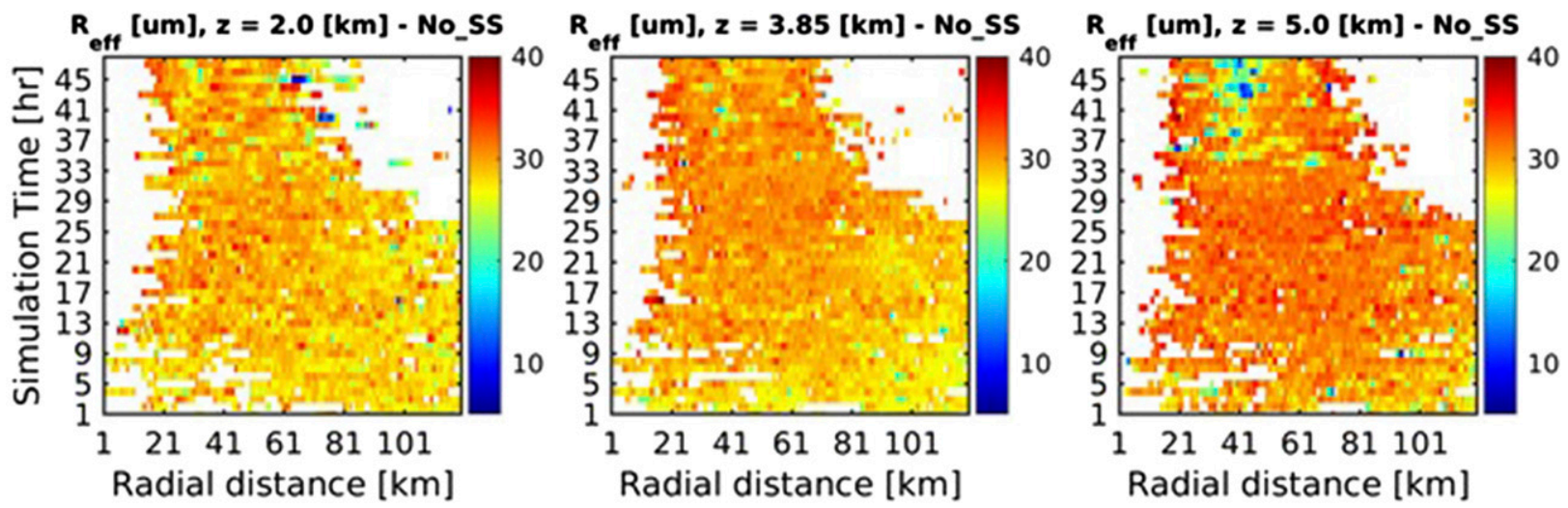

FIG. 8. Time-radial dependencies of the azimuthally averaged $r_{\text {eff }}$ at different heights in (top) Spray and (bottom) NoSpray. The values are plotted for $w>1 \mathrm{~m} \mathrm{~s}^{-1}$.

increase in $w$ and a decrease in droplet concentration by accretion.

One can see that $r_{\text {eff }}$ decreases toward areas of maximum SSP concentration [i.e., toward the regions of stronger winds (see Figs. 16 and 17)]. The tendency of $r_{\text {eff }}$ to decrease with an increase in wind speed is clearly seen also in Fig. 8, showing the time-radial dependencies of the azimuthally averaged $r_{\text {eff }}$ at different heights in Spray and NoSpray.

Figure 9 shows the dependence of the azimuthally averaged effective radius in the eyewall clouds on wind speed in Hurricanes Frances (2004) and Epsilon (2005) at the heights corresponding to the temperature of $10^{\circ} \mathrm{C}$. The values of the effective radius were derived from the Aqua and Terra satellites using the method developed by Rosenfeld and Lensky (1998). In Spray maximum wind speed increased with time (e.g., Fig. 18). At each time instance the values of the azimuthally averaged effective radii were calculated within the TC eyewall at the level of $10^{\circ} \mathrm{C}$. The asterisks in Fig. 9 denote the azimuthally averaged values of $r_{\text {eff }}$ in the eyewall clouds at different maximum wind speed in Spray. The results seem to agree well with the observations. The decrease in $r_{\text {eff }}$ with increasing surface winds is attributed to the production of larger amount of the smallest SSP with an increase in wind speed (see Fig. 1).

The formation of the drop size distribution is closely related to the values of supersaturation $S_{w}$. Figure 10 shows time-radial dependencies of the azimuthally averaged supersaturation at different heights in Spray and NoSpray plotted for regions with $w>1 \mathrm{~m} \mathrm{~s}^{-1}$. The analysis of this figure shows the following: (i) $S_{w}$ in Spray are substantially lower than in NoSpray. This result is obviously related to higher droplet concentration in Spray. (ii) The values of $S_{w}$ increases with height in both simulations, which is related to the increase in the vertical velocity and to the decrease in droplet concentration caused by accretion.

Figure 11 shows CFAD of $S_{w}$ calculated over the domain where maximum wind exceeded $25 \mathrm{~m} \mathrm{~s}^{-1}$ and $w>1 \mathrm{~m} \mathrm{~s}^{-1}$. One can see that (i) $S_{w}$ is larger in NoSpray, where the droplet concentration is much lower than in 


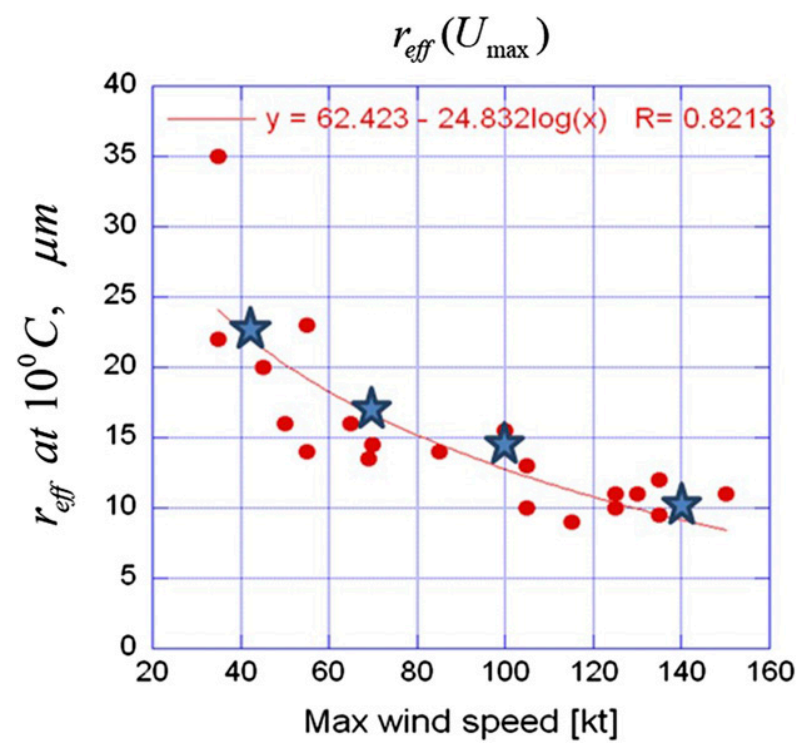

FIG. 9. Dependence of azimuthally averaged $r_{\text {eff }}$ on the maximum wind speed in Hurricanes Frances (2004) and Epsilon (2005) (red circles), measured from the Aqua and Terra satellites at the heights corresponding to the temperature of $10^{\circ} \mathrm{C}$. The stars denote the values of $r_{\text {eff }}$ obtained in Spray.

Spray; near the cloud base, $S_{w}$ is $\sim 1.5 \%$ in NoSpray and $\sim 0.2 \%$ in Spray; (ii) $S_{w}$ increases with height in both cases, but this increase in substantially higher in NoSpray; while in NoSpray, $S_{w}$ increases by $\sim 1 \%$ across the 2-km layer above the cloud base, in Spray, $S_{w}$ increases only by $0.2 \%-0.5 \%$; and (iii) in Spray, the cloud-base supersaturation maximum is not pronounced, which can be attributed to the existence of many SSP drops at cloud base.

The increase of $S_{w}$ with height seen in Figs. 10 and 11 determines the steady in-cloud nucleation of droplets, namely nucleation, which takes place continuously at all height levels above cloud base. This effect is especially important for Spray because a significant amount of the smallest SSP continue ascending without being nucleated until they reach higher levels. Such steady in-cloud nucleation determines both the low effective radius in the eyewall clouds up to high altitudes and the low values of supersaturation in Spray.

In NoSpray, the amount of small CCN is low and supersaturation is large. So most $\mathrm{CCN}$ are activated at the cloud base. Besides, because the concentration of the smallest $\mathrm{CCN}$ that remain nonactivated at supersaturations of $\sim 1.5 \%-2 \%$ is low, in-cloud nucleation in NoSpray cannot increase droplet concentration substantially. As a result, the droplet concentration remains low and droplets grow fast, as in classical maritime clouds.

Figures 5-9 show a dramatic effect of SSP on cloud droplet size. It is of interest to analyze the effect of SSP on the size of raindrops. Figure 12 shows time-height dependencies of the azimuthally averaged effective radius of raindrops (i.e., drops with radii exceeding $50 \mu \mathrm{m}$ ) in Spray and NoSpray. One can see that raindrops are larger in Spray. The difference increases with decreasing altitude, so at $z=2 \mathrm{~km}$, the effective radius of raindrops in Spray is twice as large as in NoSpray. Raindrop size in NoSpray is small as in typical deep maritime clouds (Khain and Pinsky 2018). Large raindrops can be formed either by collisions between raindrop size drops or/and by melting of graupel/hail. Both factors are present in Spray. Collisions of raindrops with these SSP rapidly lead to the appearance of large raindrops. Besides, mass and sizes of graupel/hail particles are larger in Spray (Figs. 13 and 14).

A comparison of Figs. 8 and 12 shows that the lowest values of the droplet effective radius in Spray take place where raindrops are especially large. This, again, demonstrates the unique behavior of clouds under the very large effect of SSP, where very small wet particles and raindrops can sustain and contribute to the vertical microphysical structure of the eyewall clouds.

The effect of SSP is not limited to warm microphysics but inevitably leads to changes in ice microphysics as well. Figure 13 shows radial-height cross sections of the azimuthally averaged fields of mass contents of ice crystals (small snow particles), snow, and graupel at $t=48 \mathrm{~h}$. It can be seen that including SSP leads to an increase in the ice content, which is especially pronounced at high levels above the level of homogeneous freezing. Ice crystals can also form by the nucleation of haze particles at high supersaturations above the homogeneous freezing level. Heymsfield et al. (2009) reported high values of ice number concentrations and mass contents above the homogeneous freezing level in TC.

The mass contents of snow and graupel are also larger in Spray because of the more intense accretion of small droplets at high levels. The mass content of graupel from aircraft observational study of McFarquhar and Black (2004) ranged between 0.1 and $0.6 \mathrm{~g} \mathrm{~m}^{-3}$ at $T=-11^{\circ} \mathrm{C}$. The values of graupel mass content presented in Fig. 13 do not contradict these results.

The formation of larger amounts of graupel and snow as well as larger sizes of raindrops in Spray leads to larger values of radar reflectivity in Spray as compared to NoSpray. The difference in the field of radar reflectivity is seen in Fig. 14, showing the cross sections of height-radial azimuthally averaged radar reflectivity at $t=48 \mathrm{~h}$. One can see that, in Spray, the radar reflectivity in the eyewall decreases from about $50 \mathrm{dBZ}$ at the surface to about $25 \mathrm{~dB} Z$ at $z=12 \mathrm{~km}$. These values agree well with those observed in the eyewalls of hurricanes (Heymsfield et al. 2010). In NoSpray, the radar reflectivity 


\section{Spray}
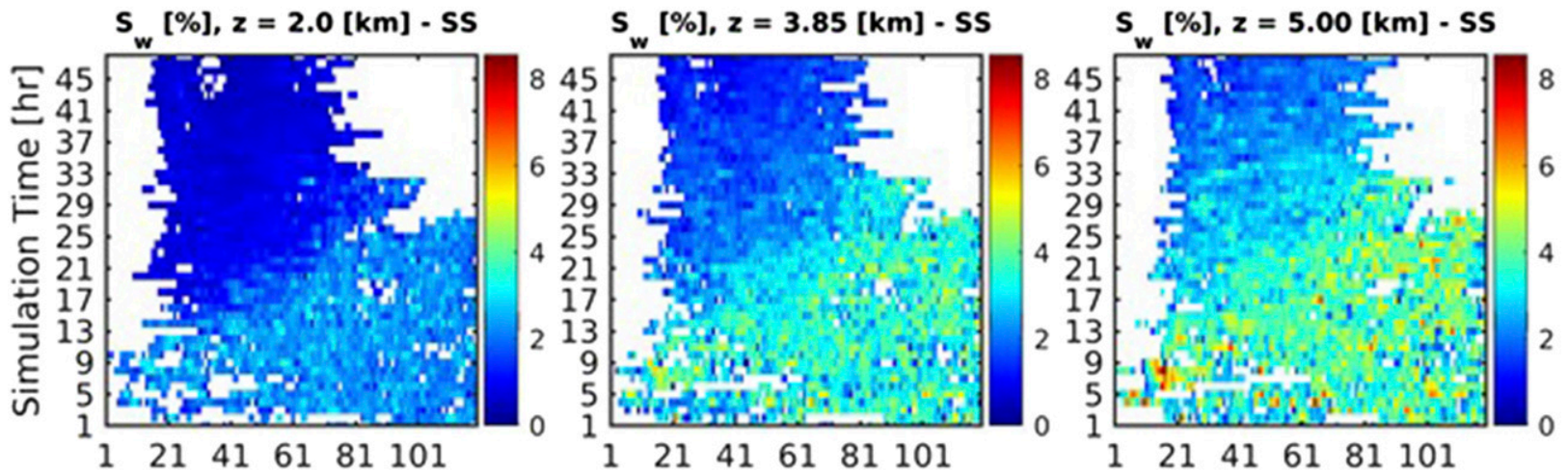

No-Spray
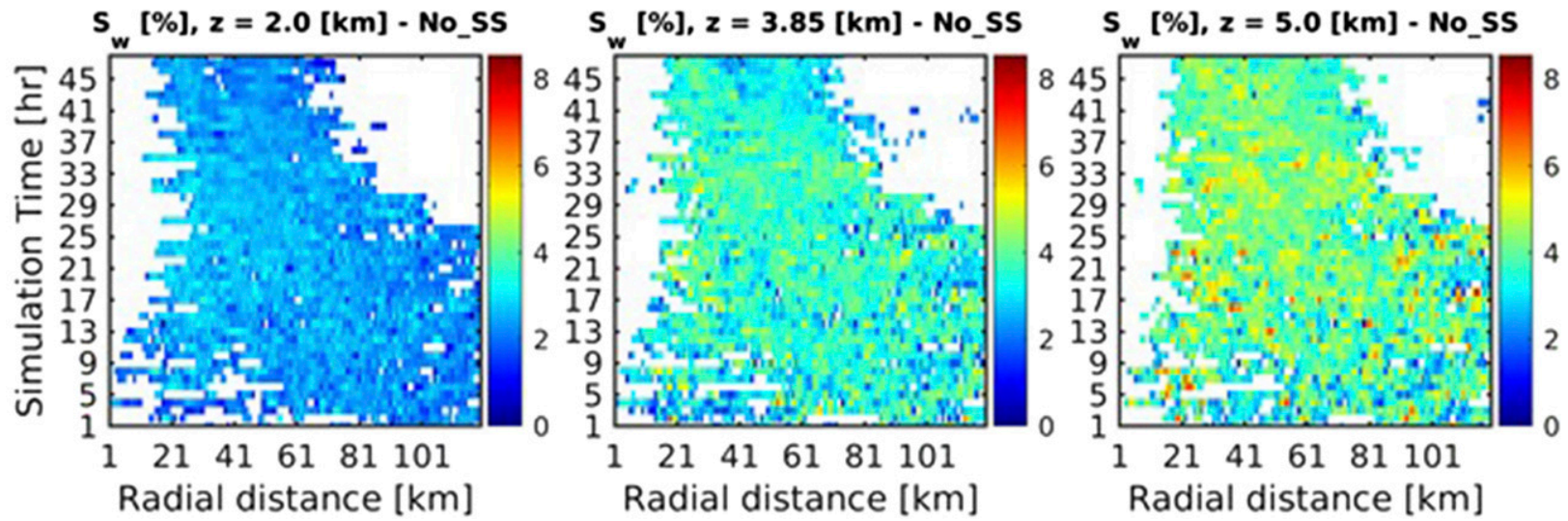

FIG. 10. Time-radial dependencies of the azimuthally averaged supersaturation at different heights in (top) Spray and (bottom) NoSpray. The values are plotted for $w>1 \mathrm{~m} \mathrm{~s}^{-1}$.

drops from about $40 \mathrm{~dB} Z$ at the surface to $\sim 10 \mathrm{~dB} Z$ at $12 \mathrm{~km}$. Such profiles are closer to those measured by Heymsfield et al. (2010) in deep convection over oceans outside TC, where the effects of SSP are negligible. It can be clearly seen that significant values of the radar reflectivity take place at $z=14 \mathrm{~km}$ and are higher in Spray, while, in NoSpray, radar reflectivity becomes very low above $13 \mathrm{~km}$. This result again agrees well with observations in the eyewalls of hurricanes and in deep tropical convection, respectively (Heymsfield et al. 2009, 2010).

\section{b. Dynamical effects of sea spray on TC}

The dynamic effect of SSP that, in part, fosters the axisymmetrization of the developing TC, was considered in the previous section in relation to Figs. 2 and 3. The results presented in section 3 a show that SSP increase liquid and ice contents, as well as the cloud-top height of the eyewall clouds. Below, we present results showing the effect of SSP on the velocity and pressure in the simulated TC. Figure 15 shows azimuthally averaged updraft velocities $(w>0)$ as a function of height and radial distance from the TC center during two time periods: $20-28 \mathrm{~h}$ (top row) and the last $5 \mathrm{~h}$ (bottom row) of the simulations in NoSpray and Spray. One can see that SSP lead to a significant increase in the vertical velocity. Since the SSP concentration increases with the magnitude of the surface wind speed, the SSP production is strongest at the distances from the TC center where the wind is maximal. Because the wind in the hurricane BL is slightly subgradient, the convergence in the $\mathrm{BL}$ is close to its maximum at the radius of maximum winds and slightly inside, closer to the TC center. The convergence in the BL determines low-level vertical velocities and the SSP vertical fluxes. These SSP ascend in the TC eyewall, quite close to the TC center. As a result, SSP 

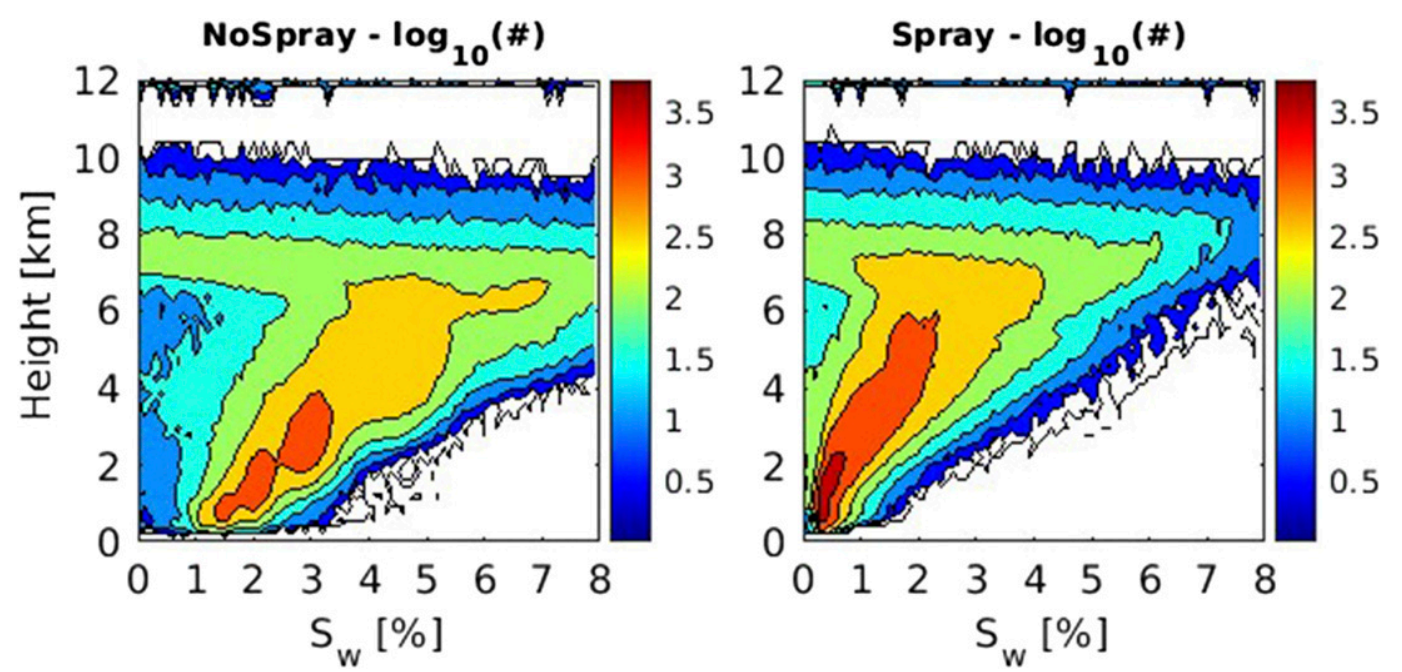

FIG. 11. Supersaturation $S_{w}$ CFAD within updrafts of at least $1 \mathrm{~m} \mathrm{~s}^{-1}$ and surface winds $>25 \mathrm{~m} \mathrm{~s}^{-1}$. The color scale shows the $\log _{10}$ of the number of occurrences as a function of $S_{w}$ and height. Calculations were performed within the range of $S_{w}$ from $0 \%$ to $8 \%$ separated into intervals of $0.1 \%$ width.

foster the formation of the axisymmetric TC structure tending to decrease the eyewall radius. This effect is clearly seen in Fig. 15. Note that the model reproduces the observed feature of vertical velocity profiles in eyewalls of hurricanes, namely, the existence of two peaks at 4-5 and around $10 \mathrm{~km}$ (Heymsfield et al. 2010). Figure 16 shows horizontal cross sections in the fields of total horizontal velocity at $z=1 \mathrm{~km}$ at different time instances in NoSpray and Spray. One can see a gradual formation of a more concentrated and more axisymmetric TC with higher maximum winds in Spray. This result is likely related to two mechanisms: thermodynamic and dynamic ones. The thermodynamic mechanism consists of the increase in latent heat release during the intensification of the eyewall convection. The dynamic mechanism agrees well with the theory of TC intensification proposed by Montgomery and Smith (2014, 2017): rapidly rotating convective elements ascending from the cloud base close to the TC center transport the angular momentum upward, which leads to an increase in the tangential velocity, leading to a more axisymmetric TC structure. The mechanism of increase in the tangential velocity in eyewall by conversion of convective-scale angular momentum to the mesoscale angular momentum was analyzed and parameterized by Khain (1984). Figure 17 shows radial-time dependencies of the difference in Spray and NoSpray between azimuthally averaged fields of surface pressure and of the wind speed at $z=10-\mathrm{m}$ and $z=1-\mathrm{km}$ levels. It is clearly seen that the TC in the Spray simulation is more intense, and the difference in the intensities increases after 22-24h. The minimum pressure shows continuing deepening, as the radial gradients are larger in Spray throughout the simulation. The horizontal wind speeds at different heights correlate quite well; the difference between the maximum wind speeds in the simulations exceeds $10 \mathrm{~m} \mathrm{~s}^{-1}$. Figure 18 shows maximum wind and minimum surface pressure time dependencies in NoSpray and Spray. One can see that SSP leads to hurricane intensification. It is of interest that a significant difference in the maximum winds arises rapidly, as soon as the effects of SSP become pronounced. This stage of TC evolution is discussed in relation to Figs. 2 and 3.

In summary, Figs. 15-18 show that SSP formation leads to an intensification of the model tropical cyclone and promotes its transformation into severe storms and hurricanes. An increase in SSP production with an increase in maximum wind constitutes a positive feedback loop that supports the intensification of the TC.

\section{Discussion and conclusions}

This is the first study of the sea spray microphysical effects on microphysical and dynamical structures of an idealized TC by means of cloud-resolving simulations using WRF with spectral bin microphysics. An idealized hurricane was simulated with 1-km grid spacing of the inner mesh. The equilibrium state SSP distributions in the HBL were simulated offline by the Lagrangian-Eulerian model at different background winds. These distributions were implemented into the HBL in areas where strong TC winds developed. Since SSP concentration increases with the surface wind, it reached its maximum at the radius of maximum wind at small distances from the storm center. These SSP, with radii ranging from 0.01 to $\sim 250 \mu \mathrm{m}$, ascend in the updraft within the eyewall, affecting the microphysics and dynamics of the eyewall clouds. 


\section{Spray}
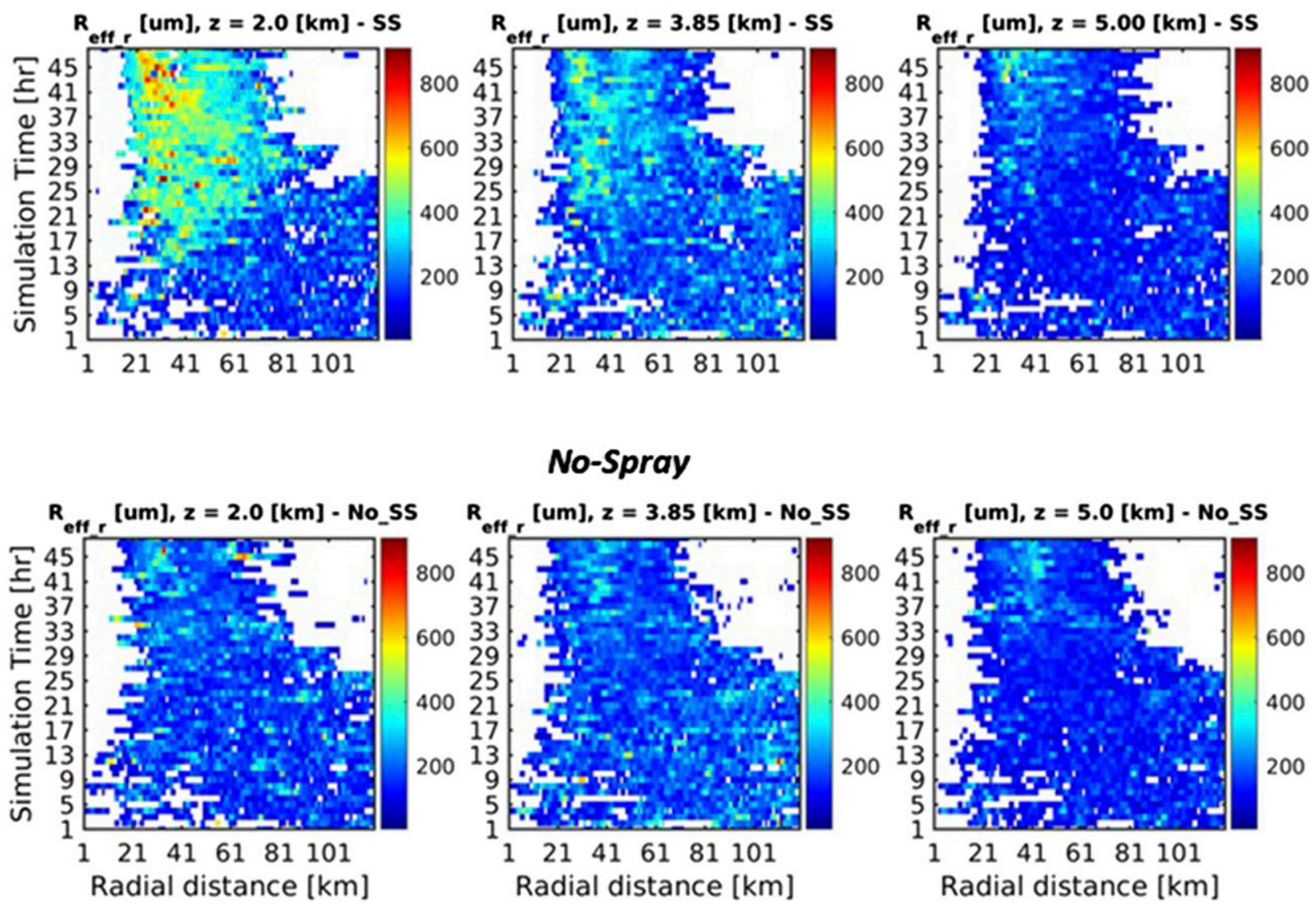

FIG. 12. Time-height dependencies of the azimuthally averaged $r_{\text {eff }}$ of raindrops ( $>50 \mu \mathrm{m}$ in radius) in (top) Spray and (bottom) NoSpray at different heights. Only those grid points where $w>1 \mathrm{~m} \mathrm{~s}^{-1}$ were analyzed.

The structure of the TC simulated with SSP taken into account are compared with that simulated by including effects of only background maritime aerosols. It is shown that, in the SSP-affected eyewall, clouds have unique properties combining both continental and maritime features. These clouds contain raindrops already at cloud base since the largest SSP are small raindrops that are intensively collecting smaller droplets. This feature is "more maritime" than that of extreme maritime clouds. At the same time, the droplet number concentration in the eyewall clouds is as high as $500-700 \mathrm{~cm}^{-3}$ below the freezing level and remains significant above this level. Such concentrations are typical of polluted continental clouds. The absence of supersaturation maximum near cloud base means a continuous increase in supersaturation with height. This induces in-cloud nucleation of the smallest $\mathrm{CCN}$, causing a high concentration of the smallest droplets up to the level of homogeneous freezing (Khain et al. 2012). As a result, the distributions of cloud droplets in the eyewall clouds have very low effective radii, not exceeding 15-17 $\mu \mathrm{m}$ until high altitudes.
The formation of such small values of the effective radius was observed from satellites. Similar to polluted continental clouds, the eyewall clouds in Spray have high CWC at high levels that are substantially larger than those in NoSpray. The eyewall clouds affected by SSP have smaller cloud droplets but larger raindrops than analogous clouds not affected by SSP. The increase in the drop number concentration and CWC in Spray foster larger amounts of snow, graupel, and ice at high levels. Therefore, in agreement with the results of SKR, SSP lead to an invigoration of the eyewall convection.

These unique properties of eyewall clouds affected by SSP allow us to explain observed features like high ice crystal concentrations in cloud anvils, intense lightning, and a low droplet effective radius-despite the considerable rainfall. In agreement with observations, the radar reflectivity in the eyewall becomes substantially higher than that in deep convective clouds in the tropics under low wind conditions.

The comparison of the results of TC simulations with and without SSP taken into account clearly shows that 

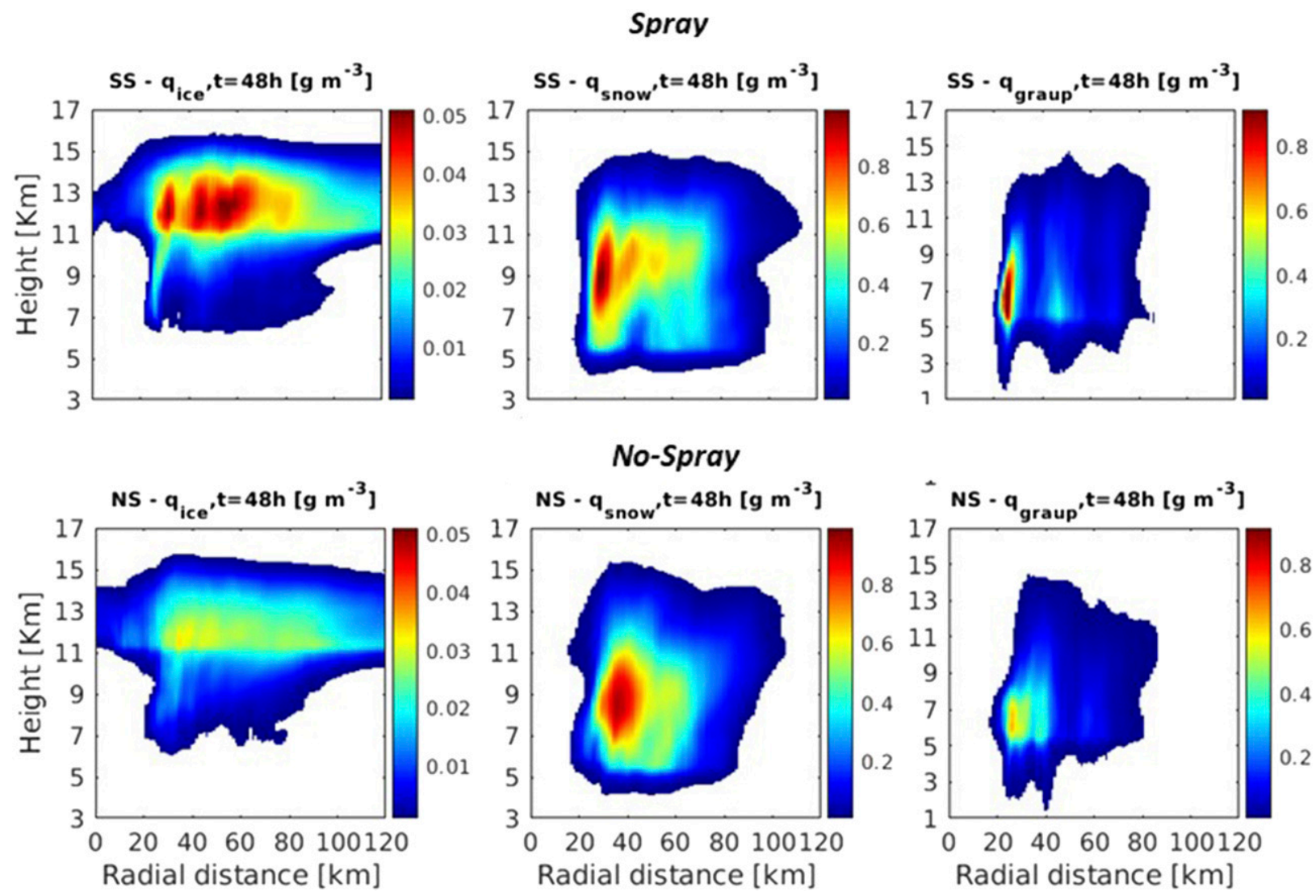

FIG. 13. Height-radial cross sections in the azimuthally averaged (left) ice crystal mixing ratio, (center) snow mixing ratio, and (right) graupel mixing ratio at $t=48 \mathrm{~h}$ in (top) Spray and (bottom) NoSpray.

SSP lead to an intensification of TC. We have shown that incorporating wind-generated SSP increases TC intensity by invigorating the inner convective cloud bands as a result of the SSP impacts on cloud microphysical processes. The increase in the SSP production with the increase in wind speed constitutes a positive feedback loop that supports intensification of the TC. Moreover, production of maximum SSP at the radius of maximum
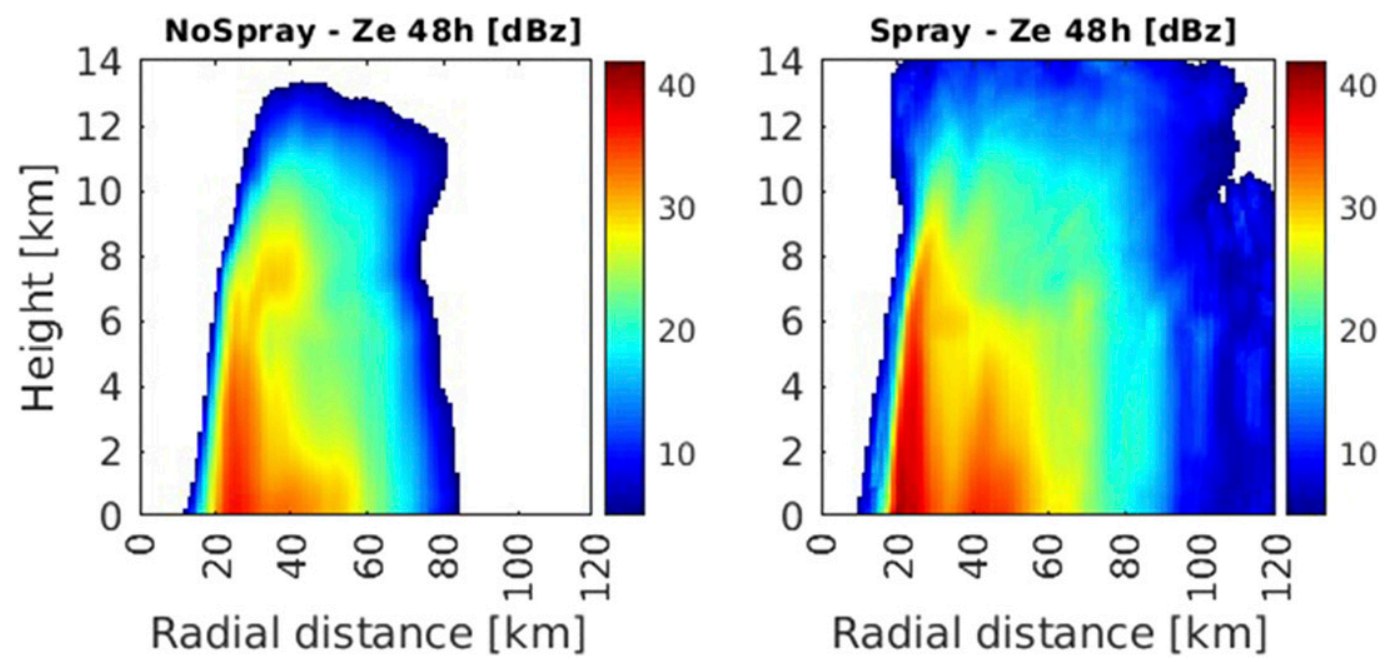

FIG. 14. Vertical cross sections of the azimuthally averaged radar reflectivity in (left) NoSpray and (right) Spray at $t=48 \mathrm{~h}$. 

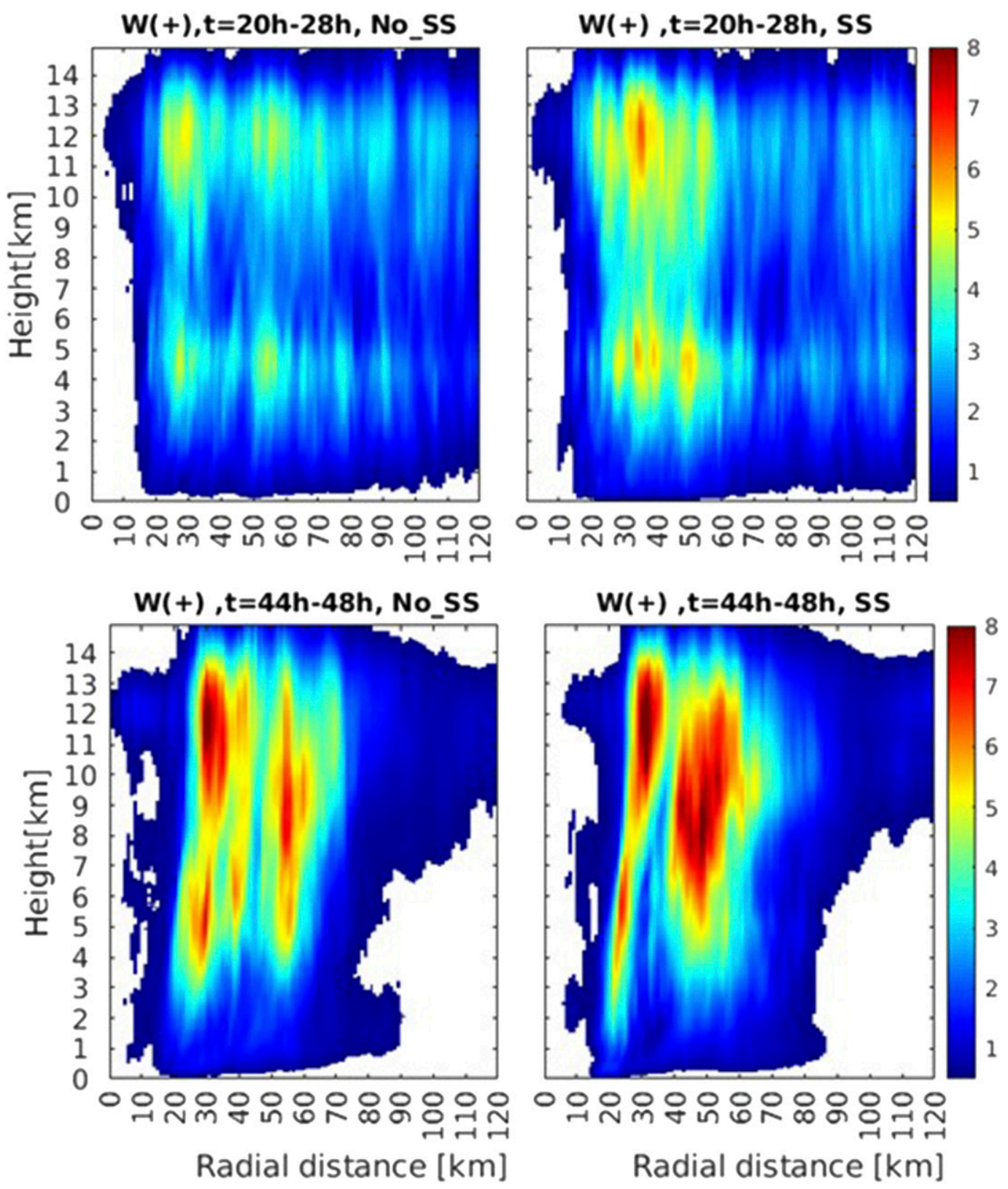

FIG. 15. Azimuthally averaged updraft velocities $\left(\mathrm{m} \mathrm{s}^{-1}\right)$ at as a function of height and radial distance from the TC center during (top) 20-28 h and (bottom) the last $5 \mathrm{~h}$ of the simulations for (left) NoSpray and (right) Spray. The averaging is done for the highest 10th percentile of the values in each instance, distance, and height.

wind leads to SSP ascending in eyewall clouds at distances from the TC center smaller than the radius of maximum winds. This makes the TC more concentrated and advances its axisymmetrization.

Note, in conclusion, that the effects of SSP are most probably underestimated in the present study. First, the grid spacing of $1 \mathrm{~km}$ that was used is not high enough to simulate realistic vertical velocities. In the LES simulations with a grid spacing of $50 \mathrm{~m}$ and similar thermodynamic conditions, the vertical velocities reach $15-18 \mathrm{~m} \mathrm{~s}^{-1}$ (see SKR). Using a 1-km grid spacing substantially decreases the maximum updrafts as compared to the LES. Accordingly, the velocity by which the cloud drops ascend is not high enough, which might decrease droplet concentration, leading to a decrease in the ice crystal concentration above, etc. The importance of grid spacing follows, for instance, from the results of a supplemental simulation with a grid spacing of $3 \mathrm{~km}$. The vertical updrafts in the supplemental simulation were about $2 \mathrm{~m} \mathrm{~s}^{-1}$, which did not permit a reproduction of the main SSP 

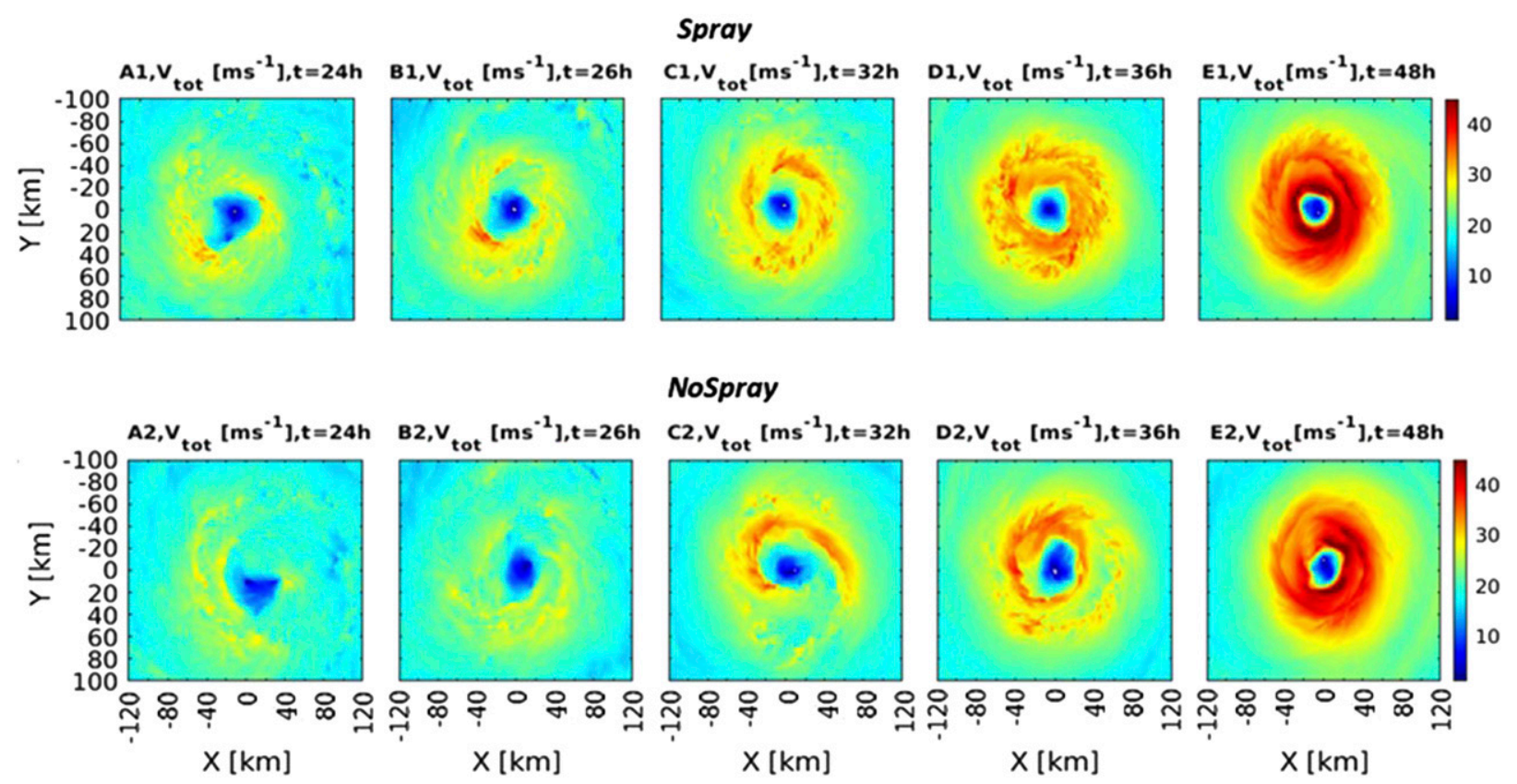

FIG. 16. Horizontal cross sections in the wind speed at $z=1 \mathrm{~km}$ for different simulation time instances in (top) Spray and (bottom) NoSpray. The color scale is chosen up to $45 \mathrm{~m} \mathrm{~s}^{-1}$ to make the differences between Spray and NoSpray distinct. Toward the end of the simulations in both runs, the wind speed exceeds $60 \mathrm{~m} \mathrm{~s}^{-1}$.

effects. Thus, the 1-km grid spacing was found to be the condition at which the SSP effects become pronounced. Second, Shpund et al. $(2012,2014)$ showed that SSP particles grow in the HBL, leading to some increase in temperature, which, in turn, may increase the atmospheric instability in the central area of the TC. Third, the SSP source at winds exceeding $50 \mathrm{~m} \mathrm{~s}^{-1}$ was assumed equal to that at $50 \mathrm{~m} \mathrm{~s}^{-1}$.

We recognize that the study has many uncertainties. The major uncertainty in this study is, supposedly, the uncertainty in the sea spray source flux strength, particularly in high wind speeds where reliable data is scarce. It is possible that the averaged SSP source fluxes we used in measurements do not fully correspond to the fluxes under real TC conditions. We recognize the importance of calculation of heat and moisture budgets and the changes in these budgets caused by SSP. It is also important to separate effects of spray on warm microphysical processes and on ice processes. We are going to include the budget calculations in next simulations of spray effect of real TC coupled with the ocean. Last, we recognize some simplifications made in the coupling process between the LEM and FSBM-2 models. These simplifications were necessary because roll vortices playing
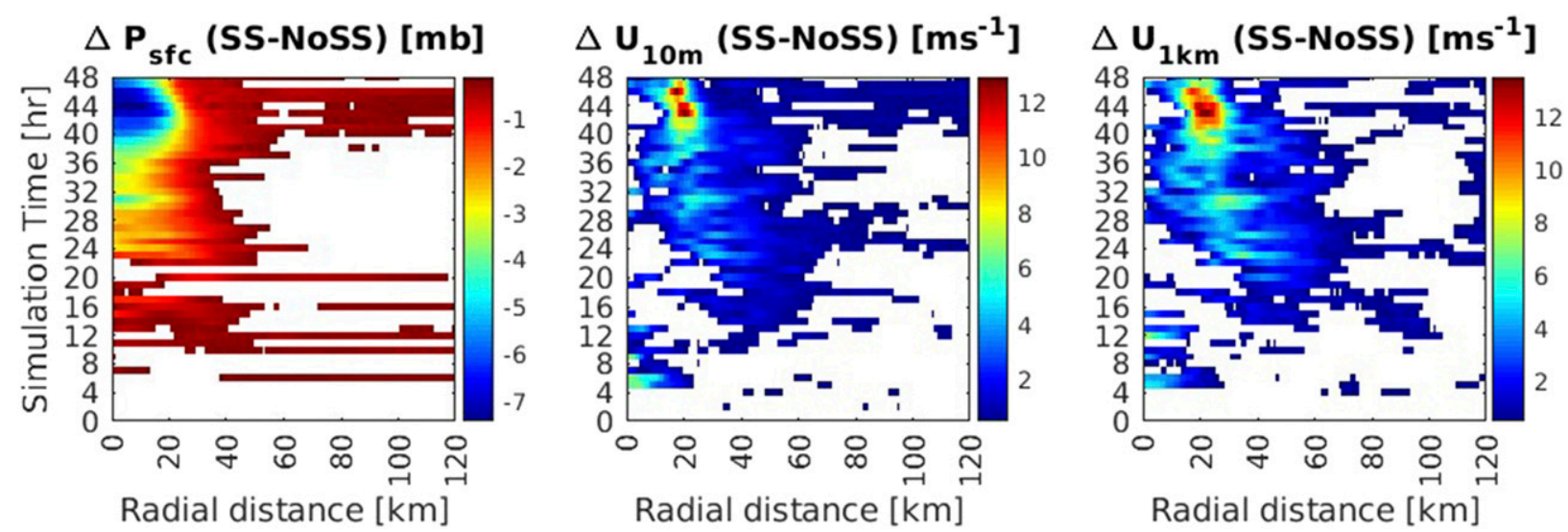

FIG. 17. Radial-time dependencies (Hovmöller diagrams) of Spray minus NoSpray differences between the azimuthally averaged fields of (left) surface pressure $(1 \mathrm{mb}=1 \mathrm{hPa})$ and wind speed at (center) $10-\mathrm{m}$ and (right) 1-km heights. 


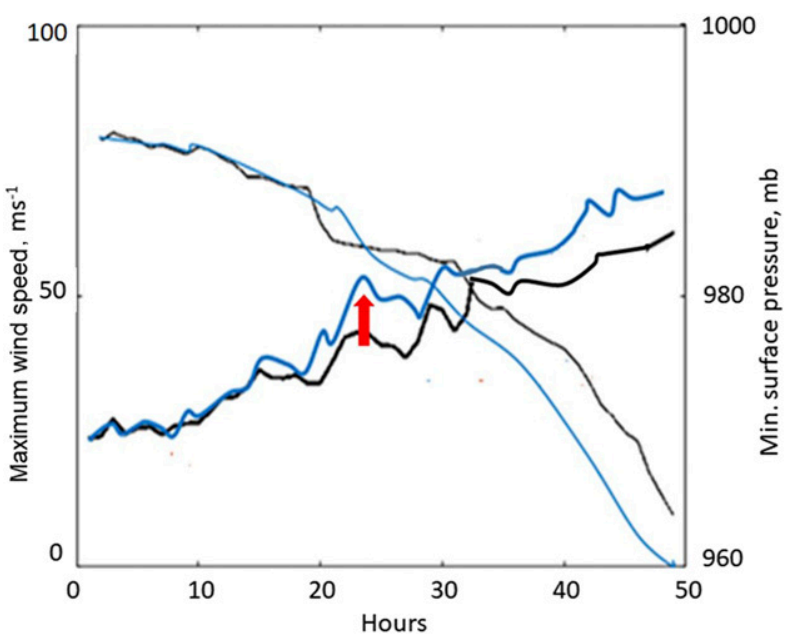

FIG. 18. Time dependencies of the maximum wind (left axis) and the minimum surface pressure (right axis) in NoSpray (black) and Spray (blue). Red arrow shows TC rapid intensification when the effect of SSP becomes pronounced.

a crucial role in the SSP transport were resolved in the LEM but are not resolved by FSBM-2, as well as because FSBM-2 does not take the SSP salinity effect on the SSP growth. Thus, the results obtained in the study require further validation. In this study, we tried to simulate the SSP effect on TCs as accurate as possible using the current SSP size distribution source flux knowledge using novel advanced models with spectral bin microphysics.

In the present study, an idealized TC with no background wind (steering current) was simulated. The simulation of a real TC with lower grid spacing of the innermost grid and higher model top is a logical next step in our investigations. We also recognize that it is important to use ensembles to provide greater depth and context for the SSP effects.

Acknowledgments. This research was supported by the Israel Science Foundation (Grants 1393/14, PI is Dr. M. Pinsky, and 2027/17, PI is Dr. A. Khain). Partial support for this work was provided from Grants DESC008811, DE-SC0014295, and ASR DE-FOA-1638 from the U.S. Department of Energy Atmospheric System Research Program (PI is A. Khain).

\section{REFERENCES}

Andreas, E. L., 1992: Sea spray and the turbulent air-sea heat fluxes. J. Geophys. Res., 97, 11 429-11 441, https://doi.org/ 10.1029/92JC00876.

__, 2004: Spray stress revisited. J. Phys. Oceanogr., 34, 1429_ 1440, https://doi.org/10.1175/1520-0485(2004)034<1429: $\mathrm{SSR}>2.0 . \mathrm{CO} ; 2$.

_ 2011: Fallacies of the enthalpy transfer coefficient over the ocean in high winds. J. Atmos. Sci., 68, 1435-1445, https:// doi.org/10.1175/2011JAS3714.1.
_ , and J. Decosmo, 1999: Sea spray production and influence on air-sea heat and moisture fluxes over the open ocean. Air-Sea Exchange: Physics, Chemistry and Dynamics, G. L. Geernaert, Ed., Atmospheric and Oceanographic Sciences Library, Vol. 20, Springer, 327-362.

— turbulent heat flux data. Bound.-Layer Meteor., 103, 303-333, https://doi.org/10.1023/a:1014564513650.

Bao, J.-W., C. W. Fairall, S. A. Michelson, and L. Bianco, 2011: Parameterizations of sea-spray impact on the air-sea momentum and heat fluxes. Mon. Wea. Rev., 139, 3781-3797, https://doi.org/ 10.1175/MWR-D-11-00007.1.

Beard, K. V., and H. T. Ochs, 1995: Collisions between small precipitation drops. Part II: Formulas for coalescence, temporary coalescence, and satellites. J. Atmos. Sci., 52, 3977-3996, https:// doi.org/10.1175/1520-0469(1995)052<3977:CBSPDP>2.0.CO;2.

Bell, M. M., M. T. Montgomery, and K. A. Emanuel, 2012: Air-sea enthalpy and momentum exchange at major hurricane wind speeds observed during CBLAST. J. Atmos. Sci., 69, 31973222, https://doi.org/10.1175/JAS-D-11-0276.1.

Benmoshe, N., M. Pinsky, A. Pokrovsky, and A. Khain, 2012: Turbulent effects on the microphysics and initiation of warm rain in deep convective clouds: 2-D simulations by a spectral mixed-phase microphysics cloud model. J. Geophys. Res., 117, D06220, https://doi.org/10.1029/2011JD016603.

Bianco, L., J. W. Bao, C. Fairall, and S. Michelson, 2011: Impact of sea-spray on the atmospheric surface layer. Bound.-Layer Meteor., 140, 361-381, https://doi.org/10.1007/s10546-011-9617-1.

Bigg, E. K., 1953: The formation of atmospheric ice crystals by the freezing of droplets. Quart. J. Roy. Meteor. Soc., 79, 510-519, https://doi.org/10.1002/qj.49707934207.

Bott, A., 1998: A flux method for the numerical solution of the stochastic collection equation. J. Atmos. Sci, 55, 2284-2293, https:// doi.org/10.1175/1520-0469(1998)055<2284:AFMFTN >2.0.CO;2.

Brown, P. S., 1997: Mass conservation considerations in analytic representation of raindrop fragment distributions. J. Atmos. Sci., 54, 1675-1687, https://doi.org/10.1175/1520-0469(1997) 054<1675:MCCIAR $>2.0 . \mathrm{CO} ; 2$.

Bye, J. A. T., and A. D. Jenkins, 2006: Drag coefficient reduction at very high wind speeds. J. Geophys. Res., 111, C03024, https:// doi.org/10.1029/2005JC003114.

Cantrell, W., and A. Heymsfield, 2005: Production of ice in tropospheric clouds: A review. Bull. Amer. Meteor. Soc., 86, 795808, https://doi.org/10.1175/BAMS-86-6-795.

Carrio, G. G., and W. R. Cotton, 2011: Investigations of aerosol impacts on hurricanes: Virtual seeding flights. Atmos. Chem. Phys., 11, 2557-2567, https://doi.org/10.5194/acp-11-2557-2011.

Clarke, A. D., S. R. Owens, and J. Zhou, 2006: An ultrafine sea-salt flux from breaking waves: Implications for cloud condensation nuclei in the remote marine atmosphere. J. Geophys. Res., 111, D06202, https://doi.org/10.1029/2005JD006565.

Cotton, W. R., H. Zhang, G. M. McFarquhar, and S. M. Saleeby, 2007: Should we consider polluting hurricanes to reduce their intensity? J. Wea. Modif., 39, 70-73.

Donelan, M. A., B. K. Haus, N. Reul, W. J. Plant, M. Stiassnie, H. C. Graber, O. B. Brown, and E. S. Saltzman, 2004: On the limiting aerodynamic roughness of the ocean in very strong winds. Geophys. Res. Lett., 31, L18306, https://doi.org/10.1029/ 2004GL019460.

Dudhia, J., 1989: Numerical study of convection observed during the Winter Monsoon Experiment using a mesoscale two-dimensional model. J. Atmos. Sci. 46, 3077-3107, https://doi.org/10.1175/15200469(1989)046<3077:NSOCOD>2.0.CO;2. 
Dunion, J. P., 2011: Rewriting the climatology of the tropical North Atlantic and Caribbean sea atmosphere. J. Climate, 24, 893908, https://doi.org/10.1175/2010JCLI3496.1.

Edson, J. B., S. Anquetin, P. G. Mestayer, and J. F. Sini, 1996: Spray droplet modeling: 2. An interactive Eulerian-Lagrangian model of evaporating spray droplets. J. Geophys. Res., 101, 1279-1293, https://doi.org/10.1029/95JC03280.

Emanuel, K. A., 1989: The finite-amplitude nature of tropical cyclogenesis. J. Atmos. Sci., 46, 3431-3456, https://doi.org/10.1175/ 1520-0469(1989)046<3431:TFANOT>2.0.CO;2.

- 2003: Tropical cyclones. Annu. Rev. Earth Planet. Sci., 31, 75104, https://doi.org/10.1146/annurev.earth.31.100901.141259.

Fairall, C. W., J. D. Kepert, and G. J. Holland, 1994: The effect of sea spray on surface energy transports over the ocean. Global Atmos. Ocean Syst., 2, 121-142.

—, M. L. Banner, W. L. Peirson, W. Asher, and R. P. Morison, 2009: Investigation of the physical scaling of sea spray spume droplet production. J. Geophys. Res., 114, C10001, https:// doi.org/10.1029/2008jc004918.

Fan, J., J. M. Comstock, M. Ovchinnikov, S. A. McFarlane, G. McFarquhar, and G. Allen, 2010: Tropical anvil characteristics and water vapor of the tropical tropopause layer: Impact of heterogeneous and homogeneous freezing parameterizations. J. Geophys. Res., 115, D12201, https://doi.org/10.1029/ 2009JD012696.

_ , and Coauthors, 2015: Improving representation of convective transport for scale-aware parameterization: 1 . Convection and cloud properties simulated with spectral bin and bulk microphysics. J. Geophys. Res. Atmos., 120, 3485-3509, https://doi.org/ 10.1002/2014JD022142.

— son of an MC3E squall line case: Part I-Convective updrafts. J. Geophys. Res. Atmos., 122, 9351-9378, https://doi.org/10.1002/ 2017JD026622.

Foster, R. C., 2005: Why rolls are prevalent in the hurricane boundary layer. J. Atmos. Sci., 62, 2647-2661, https://doi.org/ 10.1175/JAS3475.1.

Freud, E., and D. Rosenfeld, 2012: Linear relation between convective cloud drop number concentration and depth for rain initiation. J. Geophys. Res., 117, D02207, https://doi.org/ 10.1029/2011JD016457.

,,-- M. O. Andreae, A. A. Costa, and P. Artaxo, 2008: Robust relations between $\mathrm{CCN}$ and the vertical evolution of cloud drop size distribution in deep convective clouds. Atmos. Chem. Phys., 8, 1661-1675, https://doi.org/10.5194/acp-8-1661-2008.

,-- , and J. R. Kulkarni, 2011: Resolving both entrainmentmixing and number of activated $\mathrm{CCN}$ in deep convective clouds. Atmos. Chem. Phys., 11, 12 887-12 900, https://doi.org/ 10.5194/acp-11-12887-2011.

Gall, J. S., W. M. Frank, and Y. Kwon, 2008: Effects of sea spray on tropical cyclones simulated under idealized conditions. Mon. Wea. Rev., 136, 1686-1705, https://doi.org/10.1175/2007mwr2183.1.

Gao, K., and I. Ginis, 2014: On the generation of roll vortices due to the inflection point instability of the hurricane boundary layer flow. J. Atmos. Sci., 71, 4292-4307, https://doi.org/10.1175/ JAS-D-13-0362.1.

$\longrightarrow$, and - 2016: On the equilibrium-state roll vortices and their effects in the hurricane boundary layer. J. Atmos. Sci., 73, 1205-1222, https://doi.org/10.1175/JAS-D-15-0089.1.

,,- J. D. Doyle, and Y. Jin, 2017: Effect of boundary layer roll vortices on the development of an axisymmetric tropical cyclone. J. Atmos. Sci., 74, 2737-2759, https://doi.org/10.1175/ JAS-D-16-0222.1.
Ghan, S. J., and Coauthors, 2011: Droplet nucleation: Physicallybased parameterizations and comparative evaluation. J. Adv. Model. Earth Syst., 3, M10001, https://doi.org/10.1029/ 2011MS000074.

Ginis, I., A. P. Khain, and E. Morozovsky, 2004: Effects of large eddies on the structure of the marine boundary layer under strong wind conditions. J. Atmos. Sci., 61, 3049-3064, https:// doi.org/10.1175/JAS-3342.1.

Gong, S. L., 2003: A parameterization of sea-salt aerosol source function for sub- and super-micron particles. Global Biogeochem. Cycles, 17, 1097, https://doi.org/10.1029/2003GB002079.

Hallett, J., and S. C. Mossop, 1974: Production of secondary ice particles during the riming process. Nature, 249, 26-28, https:// doi.org/10.1038/249026a0.

Herbener, S. R., S. C. van den Heever, G. G. Carrió, S. M. Saleeby, and W. R. Cotton, 2014: Aerosol indirect effects on idealized tropical cyclone dynamics. J. Atmos. Sci., 71, 2040-2055, https://doi.org/10.1175/JAS-D-13-0202.1.

Heymsfield, A. J., A. Bansemer, G. Heymsfield, and A. O. Fierro, 2009: Microphysics of maritime tropical convective updrafts at temperatures from $-20^{\circ}$ to $-60^{\circ}$. J. Atmos. Sci., 66, 3530-3562, https://doi.org/10.1175/2009JAS3107.1.

,,-- M. R. Poellot, and N. Wood, 2015: Observations of ice microphysics through the melting layer. J. Atmos. Sci., $\mathbf{7 2}$, 2902-2928, https://doi.org/10.1175/JAS-D-14-0363.1.

Heymsfield, G. M., L. Tian, A. J. Heymsfield, L. Li, and S. Guimond, 2010: Characteristics of deep tropical and subtropical convection from nadir-viewing high-altitude airborne Doppler radar. J. Atmos. Sci., 67, 285-308, https://doi.org/ 10.1175/2009JAS3132.1.

Hoarau, T., C. Barthe, P. Tulet, M. Claeys, J.-P. Pinty, O. Bousquet, J. Delanoë, and B. Vié, 2018: Impact of the generation and activation of sea salt aerosols on the evolution of Tropical $\mathrm{Cy}$ clone Dumile. J. Geophys. Res. Atmos., 123, 8813-8831, https:// doi.org/10.1029/2017JD028125.

Hong, S.-Y., Y. Noh, and J. Dudhia, 2006: A new vertical diffusion package with an explicit treatment of entrainment processes. Mon. Wea. Rev., 134, 2318-2341, https://doi.org/ 10.1175/MWR3199.1.

Ilotoviz, E., A. Khain, A. V. Ryzhkov, and J. S. Snyder, 2018: Relationship between aerosols, hail microphysics, and $Z_{\mathrm{DR}}$ columns. J. Atmos. Sci., 75, 1755-1781, https://doi.org/10.1175/ JAS-D-17-0127.1.

Kamra, A. K., R. V. Bhalwankar, and A. B. Sathe, 1991: Spontaneous breakup of charged and uncharged water drops freely suspended in a wind tunnel. J. Geophys. Res., 96, 1715917 168, https://doi.org/10.1029/91JD01475.

Kepert, J., C. Fairall, and J.-W. Bao, 1999: Modelling the interaction between the atmospheric boundary layer and evaporating sea spray droplets. Air-Sea Exchange: Physics, Chemistry and Dynamics, G. L. Geernaert, Ed., Atmospheric and Oceanographic Sciences Library, Vol. 20, Springer, 363-409.

Khain, A. P., 1984: Mathematical Modeling of Tropical Cyclones. Gidrometeoizdat, $247 \mathrm{pp}$.

, 2009: Notes on state-of-the-art investigations of aerosol effects on precipitation: A critical review. Environ. Res. Lett., 4, 015004, https://doi.org/10.1088/1748-9326/4/1/015004.

, and I. L. Sednev, 1995: Simulation of hydrometeor size spectra evolution by water-water, ice-water and ice-ice interactions. Atmos. Res., 36, 107-138, https://doi.org/10.1016/ 0169-8095(94)00030-H.

_ and - 1996: Simulation of precipitation formation in the eastern Mediterranean coastal zone using a spectral micro- 
physics cloud ensemble model. Atmos. Res., 43, 77-110, https://doi.org/10.1016/S0169-8095(96)00005-1.

— and dirty atmosphere using Weather Research and Forecast Model with spectral bin microphysics. J. Geophys. Res., 114, D19209, https://doi.org/10.1029/2009JD011827.

- and M. Pinsky, 2018: Physical Processes in Clouds and Cloud Modeling. Cambridge University Press, 642 pp.

- M. Ovtchinnikov, M. Pinsky, A. Pokrovsky, and H. Krugliak, 2000: Notes on the state-of-the-art numerical modeling of cloud microphysics. Atmos. Res., 55, 159-224, https://doi.org/10.1016/ S0169-8095(00)00064-8.

—, A. Pokrovsky, M. Pinsky, A. Seifert, and V. Phillips, 2004: Effects of atmospheric aerosols on deep convective clouds as seen from simulations using a spectral microphysics mixed-phase cumulus cloud model. Part 1: Model description. J. Atmos. Sci., 61, 2963-2982, https://doi.org/10.1175/JAS-3350.1.

—_, D. Rosenfeld, and A. Pokrovsky, 2005: Aerosol impact on the dynamics and microphysics of convective clouds. Quart. J. Roy. Meteor. Soc., 131, 2639-2663, https://doi.org/10.1256/ qj.04.62.

— N. Benmoshe, and A. Pokrovsky, 2008: Factors determining the impact of aerosols on surface precipitation from clouds: An attempt of classification. J. Atmos. Sci., 65, 1721-1748, https://doi.org/10.1175/2007JAS2515.1.

— B. Bynn, and J. Dudhia, 2010: Aerosol effects on intensity of landfalling hurricanes as seen from simulations with the WRF Model with spectral bin microphysics. J. Atmos. Sci., 67, 365384, https://doi.org/10.1175/2009JAS3210.1.

— V. Phillips, N. Benmoshe, and A. Pokrovsky, 2012: The role of small soluble aerosols in the microphysics of deep maritime clouds. J. Atmos. Sci., 69, 2787-2807, https://doi.org/10.1175/ 2011JAS3649.1.

— T. V. Prabha, N. Benmoshe, G. Pandithurai, and M. Ovchinnikov, 2013: The mechanism of first raindrops formation in deep convective clouds. J. Geophys. Res. Atmos., 118, 9123-9140, https://doi.org/10.1002/jgrd.50641.

_ and Coauthors, 2015: Representation of microphysical processes in cloud-resolving models: Spectral (bin) microphysics versus bulk parameterization. Rev. Geophys., 53, 247-322, https://doi.org/10.1002/2014RG000468.

_- B. Lynn, and J. Shpund, 2016: High resolution WRF simulations of Hurricane Irene: Sensitivity to aerosols and choice of microphysical schemes. Atmos. Res., 167, 129-145, https:// doi.org/10.1016/j.atmosres.2015.07.014.

Khain, P., and Coauthors, 2019: Parameterization of vertical profiles of governing microphysical parameters of shallow cumulus cloud ensembles using LES with bin microphysics. J. Atmos. Sci., 76, 533-560, https://doi.org/10.1175/JAS-D18-0046.1.

Korolev, A. V., and I. P. Mazin, 2003: Supersaturation of water vapor in clouds. J. Atmos. Sci., 60, 2957-2974, https://doi.org/ 10.1175/1520-0469(2003)060<2957:SOWVIC >2.0.CO;2.

Kudryavtsev, V. N., and V. K. Makin, 2011: Impact of ocean spray on the dynamics of the marine atmospheric boundary layer. Bound.-Layer Meteor., 140, 383-410, https://doi.org/10.1007/ s10546-011-9624-2.

Lewis, E. R., and S. E. Schwartz, 2004: Sea Salt Aerosol Production: Mechanisms, Methods, Measurements, and Models. Geophys. Monogr., Vol. 152, Amer. Geophys. Union, 413 pp.

Li, W., 2004: Modelling air-sea fluxes during a western Pacific typhoon: Role of sea spray. Adv. Atmos. Sci., 21, 269-276, https://doi.org/10.1007/BF02915713.
Liu, B., C. Guan, and L. Xie, 2012: The wave state and sea spray related parameterization of wind stress applicable from low to extreme winds. J. Geophys. Res., 117, C00J22, https://doi.org/ 10.1029/2012JB009290.

Lorsolo, S., J. L. Schroeder, P. Dodge, and F. Marks, 2008: An observational study of hurricane boundary layer small-scale coherent structures. Mon. Wea. Rev., 136, 2871-2893, https:// doi.org/10.1175/2008MWR2273.1.

Low, T. B., and R. List, 1982: Collision, coalescence and breakup of raindrops. Part I: Experimentally established coalescence efficiencies and fragment size distributions in breakup. J. Atmos. Sci., 39, 1591-1606, https://doi.org/10.1175/1520-0469(1982) $039<1591$ :CCABOR $>2.0 . \mathrm{CO} ; 2$.

Lynn, B. H., and Coauthors, 2016: The sensitivity of Hurricane Irene to aerosols and ocean coupling: Simulations with WRF spectral bin microphysics. J. Atmos. Sci., 73, 467-486, https:// doi.org/10.1175/JAS-D-14-0150.1.

Magaritz, L., M. Pinsky, A. Khain, and O. Krasnov, 2009: Investigation of droplet size distributions and drizzle formation using a new trajectory ensemble model. Part II: Lucky parcels. J. Atmos. Sci., 66, 781-805, https://doi.org/10.1175/ 2008JAS2789.1.

Mårtensson, E. M., E. D. Nilsson, G. de Leeuw, L. H. Cohen, and H. C. Hansson, 2003: Laboratory simulations and parameterization of the primary marine aerosol production. J. Geophys. Res., 108, 4297, https://doi.org/10.1029/2002JD002263.

McFarquhar, G. M., and R. A. Black, 2004: Observations of particle size and phase in tropical cyclones: Implications for mesoscale modeling of microphysical processes. J. Atmos. Sci., 61, 422-439, https://doi.org/10.1175/1520-0469(2004) 061<0422:OOPSAP $>2.0$. CO 2 .

Mlawer, E. J., S. J. Taubman, P. D. Brown, M. J. Iacono, and S. A. Clough, 1997: Radiative transfer for inhomogeneous atmospheres: RRTM, a validated correlated-k model for the longwave. J. Geophys. Res., 102, 16 663-16 682, https://doi.org/ 10.1029/97JD00237.

Montgomery, M. T., and R. K. Smith, 2014: Paradigms for tropical cyclone intensification. Aust. Meteor. Oceanogr. J., 64, 37-66, https://doi.org/10.22499/2.6401.005.

— and - 2017: Recent developments in the fluid dynamics of tropical cyclones. Annu. Rev. Fluid Mech., 49, 541-574, https:// doi.org/10.1146/annurev-fluid-010816-060022.

Mossop, S. C., 1976: Production of secondary ice particles during the growth of graupel by riming. Quart. J. Roy. Meteor. Soc., 102, 25-44, https://doi.org/10.1002/qj.49710243104.

Mueller, J. A., and F. Veron, 2010: A Lagrangian stochastic model for sea-spray evaporation in the atmospheric marine boundary layer. Bound.-Layer Meteor., 137, 135-152, https://doi.org/ 10.1007/s10546-010-9520-1.

_, and — 2014a: Impact of sea spray on air-sea fluxes. Part I: Results from stochastic simulations of sea spray drops over the ocean. J. Phys. Oceanogr., 44, 2817-2834, https://doi.org/ 10.1175/JPO-D-13-0245.1.

$\longrightarrow$, and — 2014b: Impact of sea spray on air-sea fluxes. Part II: Feedback effects. J. Phys. Oceanogr., 44, 2835-2853, https:// doi.org/10.1175/JPO-D-13-0246.1.

Ovadnevaite, J., A. Manders, G. de Leeuw, D. Ceburnis, C. Monahan, A.-I. Partanen, H. Korhonen, and C. D. O'Dowd, 2014: A sea spray aerosol flux parameterization encapsulating wave state. Atmos. Chem. Phys., 14, 1837-1852, https://doi.org/10.5194/ acp-14-1837-2014.

Perrie, W., W. L. Zhang, E. Andreas, W. Li, J. Gyakum, and R. McTaggart-Cowan, 2005: Sea spray impacts on intensifying 
midlatitude cyclones. J. Atmos. Sci., 62, 1867-1883, https:// doi.org/10.1175/JAS3436.1.

Pinsky, M. B., and A. P. Khain, 2002: Effects of in-cloud nucleation and turbulence on droplet spectrum formation in cumulus clouds. Quart. J. Roy. Meteor. Soc., 128, 501-533, https://doi.org/ 10.1256/003590002321042072.

,-- , and M. Shapiro, 2001: Collision efficiency of drops in a wide range of Reynolds numbers: Effects of pressure on spectrum evolution. J. Atmos. Sci., 58, 742-764, https://doi.org/ 10.1175/1520-0469(2001)058<0742:CEODIA >2.0.CO;2.

,$- \ldots$, and L. Magaritz, 2010: Representing turbulent mixing of non-conservative values in Eulerian and Lagrangian cloud models. Quart. J. Roy. Meteor. Soc., 136, 1228-1242, https:// doi.org/10.1002/qj.624.

,-- I. Mazin, and A. Korolev, 2012: Analytical estimation of droplet concentration at cloud base. J. Geophys. Res., 117, D18211, https://doi.org/10.1029/2012JD017753.

— I. P. Mazin, A. Korolev, and A. P. Khain, 2013: Supersaturation and diffusional droplet growth in liquid clouds. J. Atmos. Sci., 70, 2778-2793, https://doi.org/10.1175/JAS-D-12-077.1.

,,--- , and,- 2014 : Supersaturation and diffusional droplet growth in liquid clouds: Polydisperse spectra. J. Geophys. Res. Atmos., 119, 12 872-12 887, https://doi.org/ 10.1002/2014JD021885.

Powell, M. D., P. J. Vickery, and T. A. Reinhold, 2003: Reduced drag coefficient for high wind speeds in tropical cyclones. Nature, 422, 279-283, https://doi.org/10.1038/nature01481.

Prabha, T. V., A. Khain, R. S. Maheshkumar, G. Pandithurai, J. R. Kulkarni, M. Konwar, and B. N. Goswami, 2011: Microphysics of premonsoon and monsoon clouds as seen from in situ measurements during the Cloud Aerosol Interaction and Precipitation Enhancement Experiment (CAIPEEX). J. Atmos. Sci., 68, 1882-1901, https://doi.org/ 10.1175/2011JAS3707.1.

Qu, Y., B. Chen, J. Ming, B. H. Lynn, and M.-J. Yang, 2017: Aerosol impacts on the structure, intensity, and precipitation of the landfalling Typhoon Saomai (2006). J. Geophys. Res. Atmos., 122, 11 825-11 842, https://doi.org/10.1002/2017JD027151.

Rosenfeld, D., and I. M. Lensky, 1998: Satellite-based insights into precipitation formation processes in continental and maritime convective clouds. Bull. Amer. Meteor. Soc., 79, 2457-2476, https:// doi.org/10.1175/1520-0477(1998)079<2457:SBIIPF>2.0.CO;2.

—, R. Lahav, A. P. Khain, and M. Pinsky, 2002: The role of sea spray in cleaning air pollution over ocean via cloud processes. Science, 297, 1667-1670, https://doi.org/10.1126/science.1073869.

— W. L. Woodley, A. Khain, W. R. Cotton, G. Carrió, I. Ginis, and J. H. Golden, 2012: Aerosol effects on microstructure and intensity of tropical cyclones. Bull. Amer. Meteor. Soc., 93, 987-1001, https://doi.org/10.1175/BAMS-D-11-00147.1.

Ryzhkov, A., M. Pinsky, A. Pokrovsky, and A. Khain, 2011: Polarimetric radar observation operator for a cloud model with spectral microphysics. J. Appl. Meteor. Climatol., 50, 873-894, https://doi.org/10.1175/2010JAMC2363.1.

Seifert, A., A. Khain, U. Blahak, and K. D. Beheng, 2005: Possible effects of collisional breakup on mixed-phase deep convection simulated by a spectral (bin) cloud model. J. Atmos. Sci., 62 , 1917-1931, https://doi.org/10.1175/JAS3432.1.

Shpund, J., M. Pinsky, and A. Khain, 2011: Microphysical structure of the marine boundary layer under strong wind and spray formation as seen from simulations using a 2D explicit microphysical model. Part I: The impact of large eddies. J. Atmos. Sci., 68, 2366-2384, https://doi.org/10.1175/ 2011JAS3652.1.

_ J J. A. Zhang, M. Pinsky, and A. Khain, 2012: Microphysical structure of the marine boundary layer under strong wind and spray formation as seen from simulations using a $2 \mathrm{D}$ explicit microphysical model. Part II: The role of sea spray. J. Atmos. Sci., 69, 3501-3514, https://doi.org/10.1175/JAS-D-11-0281.1.

,,$-- \ldots$, and,- 2014 : Microphysical structure of the marine boundary layer under strong wind and sea spray formation as seen from a 2D explicit microphysical model. Part III: Parameterization of height-dependent droplet size distribution. J. Atmos. Sci., 71, 1914-1934, https://doi.org/10.1175/ JAS-D-12-0201.1.

—_ A. Khain, and D. Rosenfeld, 2019: Effects of sea spray on microphysics and intensity of deep convective clouds. J. Geophys. Res., in press.

Snyder, J. C., A. V. Ryzhkov, M. R. Kumjian, A. P. Khain, and J. Picca, 2015: A $Z_{\mathrm{DR}}$ column detection algorithm to examine convective storm updrafts. Wea. Forecasting, 30, 1819-1844, https://doi.org/10.1175/WAF-D-15-0068.1.

Soloviev, A., and R. Lukas, 2010: Effects of bubbles and sea spray on air-sea exchange in hurricane conditions. Bound.-Layer Meteor., 136, 365-376, https://doi.org/10.1007/s10546-010-9505-0.

,,-- M. A. Donelan, B. K. Haus, and I. Ginis, 2015: The airsea interface and surface stress under tropical cyclones. Sci. Rep., 4, 5306, https://doi.org/10.1038/srep05306.

Srivastava, R. C., 1971: Size distribution of raindrops generated by their breakup and coalescence. J. Atmos. Sci., 28, 410-415, https:// doi.org/10.1175/1520-0469(1971)028<0410:SDORGB >2.0.CO;2.

Tao, W.-K., J.-P. Chen, Z. Li, C. Wang, and C. Zhang, 2012: Impact of aerosols on convective clouds and precipitation. Rev. Geophys., 50, RG2001, https://doi.org/10.1029/2011RG000369.

Veron, F., 2015: Ocean spray. Annu. Rev. Fluid Mech., 47, 507-538, https://doi.org/10.1146/annurev-fluid-010814-014651.

Wang, Y. Q., J. D. Kepert, and G. J. Holland, 2001: The effect of sea spray evaporation on tropical cyclone boundary layer structure and intensity. Mon. Wea. Rev., 129, 2481-2500, https://oi.org/ 10.1175/1520-0493(2001)129<2481:TEOSSE $>2.0$. CO;2.

Zhang, J. A., K. B. Katsaros, P. G. Black, S. Lehner, J. R. French, and W. M. Drennan, 2008: Effects of roll vortices on turbulent fluxes in the hurricane boundary layer. Bound.-Layer Meteor., 128, 173-189, https://doi.org/10.1007/s10546-008-9281-2.

— W. M. Drennan, P. G. Black, and J. R. French, 2009: Turbulence structure of the hurricane boundary layer between the outer rainbands. J. Atmos. Sci., 66, 2455-2467, https://doi.org/ 10.1175/2009JAS2954.1.

Zhu, P., 2008: Simulation and parameterization of the turbulent transport in the hurricane boundary layer by large eddies. J. Geophys. Res., 113, D17104, https://doi.org/10.1029/ 2007JD009643. 